\title{
The mRNA-bound proteome of the human malaria parasite Plasmodium falciparum
}

\author{
Evelien M. Bunnik', Gayani Batugedara', Anita Saraf², Jacques Prudhomme1, Laurence Florens² \\ and Karine G. Le Roch ${ }^{1 *}$
}

\begin{abstract}
Background: Gene expression is controlled at multiple levels, including transcription, stability, translation, and degradation. Over the years, it has become apparent that Plasmodium falciparum exerts limited transcriptional control of gene expression, while at least part of Plasmodium's genome is controlled by post-transcriptional mechanisms. To generate insights into the mechanisms that regulate gene expression at the post-transcriptional level, we undertook complementary computational, comparative genomics, and experimental approaches to identify and characterize mRNA-binding proteins (mRBPs) in P. falciparum.

Results: Close to 1000 RNA-binding proteins are identified by hidden Markov model searches, of which mRBPs encompass a relatively large proportion of the parasite proteome as compared to other eukaryotes. Several abundant mRNA-binding domains are enriched in apicomplexan parasites, while strong depletion of mRNA-binding domains involved in RNA degradation is observed. Next, we experimentally capture 199 proteins that interact with mRNA during the blood stages, 64 of which with high confidence. These captured mRBPs show a significant overlap with the in silico identified candidate RBPs $(p<0.0001)$. Among the experimentally validated mRBPs are many known translational regulators active in other stages of the parasite's life cycle, such as DOZI, CITH, PfCELF2, Musashi, and PfAlba1-4. Finally, we also detect several proteins with an RNA-binding domain abundant in Apicomplexans (RAP domain) that is almost exclusively found in apicomplexan parasites.
\end{abstract}

Conclusions: Collectively, our results provide the most complete comparative genomics and experimental analysis of mRBPs in P. falciparum. A better understanding of these regulatory proteins will not only give insight into the intricate parasite life cycle but may also provide targets for novel therapeutic strategies.

Keywords: Gene expression, Post-transcriptional regulation, Protein domains, RNA-binding proteins, Translation

\section{Background}

Malaria continues to contribute significantly to the global burden of disease, with an estimated 438,000 deaths and 214 million infected individuals in 2014 [1], the majority of which were caused by the most deadly human malaria parasite, Plasmodium falciparum. Despite continued efforts aimed at preventing infections, treatment of infected individuals is still an essential part of the strategy to reduce malaria morbidity and mortality. Given the importance of treatment in the control of malaria, the spread of drug-resistant parasites is

\footnotetext{
* Correspondence: karine.leroch@ucr.edu

${ }^{1}$ Department of Cell Biology and Neuroscience, University of California,

Riverside, 900 University Avenue, Riverside, CA 92521, USA

Full list of author information is available at the end of the article
}

alarming $[2,3]$ and calls for the development of novel antimalarial drugs.

Since the completion of the P. falciparum genome over a decade ago [4], much effort has been put into deciphering patterns of gene expression in the parasite, motivated by the notion that this will increase our understanding of parasite biology and reveal attractive targets for novel antimalarial drugs [5-7]. In addition, the process of gene regulation is governed by essential regulatory components that by themselves could be novel drug targets.

Gene expression is controlled at multiple levels by means of mechanisms that regulate gene transcription or that act post-transcriptionally to affect the stability or translational efficiency of the transcript. Over the years, it has become apparent that $P$. falciparum exerts limited 
control of gene expression at the level of transcription. The number of transcription-associated proteins, such as specific transcription factors and subunits of the mediator complex, is relatively low in both $P$. falciparum and the second most prevalent human malaria parasite, P. vivax, as compared to other eukaryotes [8-11]. In addition, strong epigenetic control of gene expression is only observed for several gene families involved in antigenic variation [12, 13]. On the other hand, various studies have found discrepancies between steady-state mRNA levels and protein abundance or levels of protein synthesis, with a delay in translation for a subset of genes [14-17], suggesting that at least part of Plasmodium's genome is controlled by post-transcriptional mechanisms.

Post-transcriptional mechanisms of gene regulation are centered around RNA-binding proteins (RBPs), several of which have been shown to play important roles in parasite biology, in particular during the transmission stages. Plasmodium species lack homologs of the RNA interference machinery [18], and mechanisms of posttranscriptional control that have thus far been identified in the parasite are based on translational repression by stabilization and storage of transcripts. In sporozoites, an RBP of the Pumilio/FBF family PUF2 (PF3D7_0417100) is essential for maintaining translational repression resulting in latency [19-22]. In female gametocytes, hundreds of transcripts are translationally repressed during the transformation into ookinetes in the mosquito midgut [23]. The ATP-dependent RNA helicase DDX6 (DOZI; PF3D7_0320800) and a homolog of CAR-I in fly and Trailer Hitch in worm (CITH; PF3D7_1474900) regulate the storage of these transcripts into ribonucleoprotein complexes in the cytoplasm of the female gametocyte $[24,25]$. In addition, PUF2 represses the translation of a number of gametocyte transcripts [26], but it does not seem to be present in the DOZI- and CITH-dependent RNA granules.

Several RBPs have been shown to be involved in posttranscriptional regulation of gene expression during the intraerythrocytic developmental cycle (IDC). PfCAF1 (PF3D7_0811300) and PfAlba1 (PF3D7_0814200) both regulate hundreds of transcripts and are particularly important for stabilization of transcripts encoding egress and invasion proteins [27, 28]. In addition, PfSR1 (PF3D7_0517300) controls alternative splicing and transcript abundance for a subset of genes [29]. However, little is known about other RBPs that are expressed during the IDC and their role in mRNA homeostasis.

A recent bioinformatics analysis by Reddy et al. cataloged RBPs with the common RNA recognition motif (RRM) and RNA helicase motifs, as well as several other less common RNA-binding domains (RBDs) [30]. However, many additional RNA-binding motifs have been identified in other eukaryotic genomes. We therefore undertook a comprehensive computational and comparative genomics approach to generate an extended atlas of RBPs in P. falciparum. In addition, we provide experimental evidence for a role of a subset of these RBPs during the IDC of the parasite. Our results validate that mechanisms regulating translation are most likely complex. A better understanding of these regulatory RBPs will not only provide insights into the intricate life cycle of this deadly parasite, but will also assist the identification of novel targets for therapeutic strategies.

\section{Results \\ Identification and classification of RNA-binding proteins in $P$. falciparum}

To characterize the repertoire of RNA-binding proteins (RBPs) in P. falciparum, we performed a hidden Markov model (HMM) search on the parasite proteome using 793 domains from the protein family (Pfam) database that are known to interact with RNA or that are found in RNA-related proteins (Additional file 1). These domains cover the complete range of RNA-related cellular functions, including biogenesis, modification, and degradation of tRNA, rRNA, mRNA, and other RNAs, as well as GTPase and ATPase activities. In a similar approach, this collection of RNA-binding domains (RBDs) has recently been used to generate an atlas of RBPs in humans [31]. Our HMM search identified 924 P. falciparum proteins that contain RBDs. This list of candidate RBPs was manually completed by including 64 proteins lacking an RBD, but that have annotated RNA-binding activity according to the information available in PlasmoDB, resulting in a total of 988 RBP candidates, or $18.1 \%$ of the total $P$. falciparum proteome.

The most common RBDs among P. falciparum proteins were observed to be RRMs (discussed in detail by Reddy et al. [30]), which were found in 77 proteins, followed by the MMR_HSR1 GTPase domain (67 members), the DEAD box helicase domain (64 members, see also [30]), and the GTP-binding elongation factor domain family (GTP_EFTU, GTP_EFTU_D2, and GTP_EFTU_D3; 53 members). For the RBDs that are present in eight or more proteins, we determined the structural features of the RBP candidates. Many proteins with RRM domains contain multiple instances of these domains or are combined with other RBDs, providing increased sequence specificity and binding affinity to the RBP [32] (Fig. 1a and Additional file 2). In contrast, DEAD box helicase, RNA helicase, and several other domains were often found in combination with non-RNA-related Pfam domains. As an exception, most LSm proteins almost exclusively harbor a single LSm domain and no other Pfam domains, indicative of their highly specialized function in mRNA splicing and degradation [33]. The majority (205 out of 230 proteins; $89 \%$ ) of RBPs described by Reddy et al. are confirmed in 


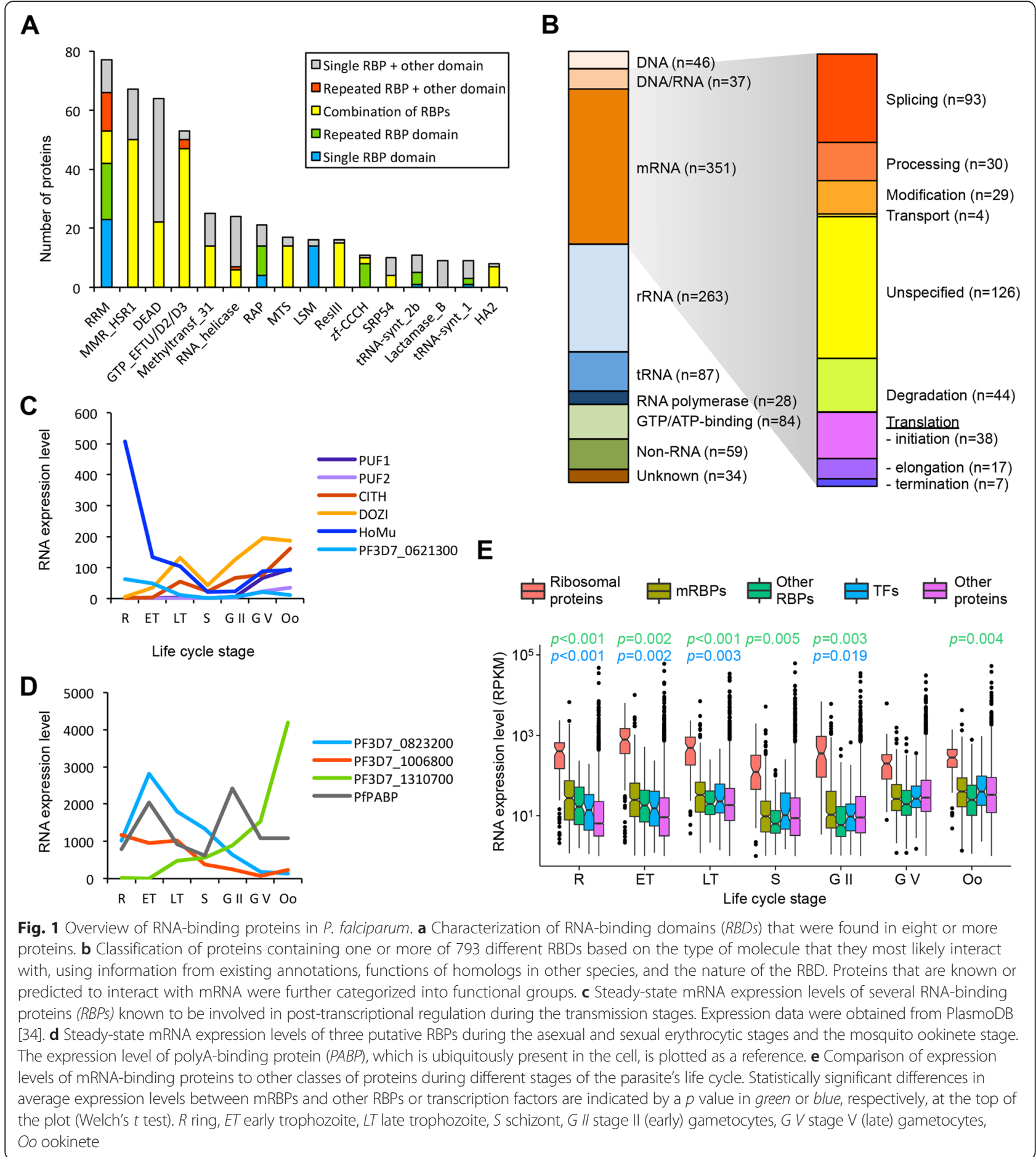

this study. Our HHM search identified four additional RRM proteins and 13 additional DEAD/DEXD helicases, but did not validate all zinc finger proteins and $\mathrm{KH}$ domain-containing proteins listed by Reddy et al. (Additional file 3: Figure S1).

The RBP candidates were then categorized based on the type of molecule that they most likely interact with, using information from existing annotations, functions of homologs in other species, and the nature of the RBD (Fig. 1b and Additional file 2). Out of 988 RBP candidates, 737 proteins ( $13.5 \%$ of the proteome) have known or predicted RNA-related functions, including interactions with messenger RNA $(n=351)$, ribosomal RNA $(n=263)$, and transfer RNA $(n=86)$. A total of 46 
proteins are most likely to bind to DNA, while 37 proteins may interact with either DNA or RNA, or both. A further 84 proteins have GTP- or ATP-binding activity, while 93 proteins have either no known function or a non-RNA-related annotation. The candidate messenger RNA-binding proteins (mRBPs, $n=388$ including proteins that interact with either DNA or RNA) were further subdivided into functional categories: splicing, processing, modification, transport, degradation, translation initiation, translation elongation, and translation termination (Fig. $1 \mathrm{~b}$ and Additional file 2).

A large fraction of candidate mRBPs $(n=126,35.0 \%)$ has known or predicted RNA-binding activity, but does not fall into any of the functional categories mentioned above. Several of these mRBPs have well-documented roles in post-transcriptional gene regulation, such as PUF2, DOZI, and CITH. Accordingly, these genes are most highly expressed in gametocytes and ookinetes, although they are also detected at lower levels during the asexual stages (Fig. 1c). Interestingly, Homolog of Musashi (HoMu; PF3D7_0916700), which has also been implicated in translational repression in gametocytes [25], and mRNA-binding Pumilio-homology domain protein (PF3D7_0621300) are both most highly expressed early in the IDC (Fig. 1c), raising the possibility that similar mechanisms of translational control occur during the IDC. Many proteins are merely annotated as putative RBPs without a specified function and typically contain multiple RRM domains. Some of these putative RBPs are among the top $1 \%$ in terms of RNA-Seq gene expression [34], suggesting that they play important roles in RNA metabolism. Examples are PF3D7_0823200 and PF3D7_1006800, which are highly expressed during the IDC, and putative RBP PF3D7_1310700, which is highly abundant in ookinetes (Fig. 1d). PF3D7_0823200 has homology with CELF proteins, although its RBD architecture is different from that of CELF proteins in other organisms [30, 35]. PF3D7_1006800 has homology to G-strand binding protein 2 (Gbp2p; suggested annotation PfSrrm5) in other organisms [30] and may thus be involved in export of spliced mRNAs from the nucleus to the cytoplasm. Overall, the gene expression data also show that in many stages of the parasite's life cycle the average expression level of mRBPs is higher than for other RBPs (Fig. 1e). In addition, mRBPs are on average more highly expressed than general and specific transcription factors during most of the IDC and in early gametocytes, indicative of their importance for gene regulation.

\section{Comparative analysis of RNA-binding proteins in apicomplexan parasites and other eukaryotes}

To better understand the roles of RBPs in parasite biology, we next performed a comprehensive comparison of
RBDs among a variety of organisms. Since the full set of 793 RBDs contains many domains typically found in proteins that interact with DNA, rRNA, or tRNA, this list was manually curated to include only known or putative mRNA-binding domains (mRBDs; $n=372$ ). We then performed HMM searches on the proteomes of two additional apicomplexan parasites ( $P$. vivax and Toxoplasma gondii), three euglenid parasites (Trypanosoma brucei, Trypanosoma cruzii, and Leishmania major), two unicellular organisms (Saccharomyces cerevisiae and Schizosaccharomyces pombe), and three multicellular organisms (Homo sapiens, Caenorhabditis elegans, and Drosophila melanogaster) to find proteins that contain any of these mRBDs. To ensure that the HMM seeds were not biased towards apicomplexan organisms, we calculated the percentage of sequences in the HMM seeds derived from apicomplexa, euglenids, fungi, and metazoa. For only 7 out of 372 mRBDs, more than $25 \%$ of the sequences in the HMM seed were derived from apicomplexan parasites, while a total of 178 and 165 mRBDs were biased towards fungi and metazoa, respectively (Additional file 4). Plasmodium species harbor a relatively high number of candidate mRBPs as compared to other organisms: $9.6 \%$ of the full $P$. falciparum proteome and $9.5 \%$ of the full $P$. vivax proteome contain mRBDs, similar to Saccharomyces species $(9.8 \%$ for S. cerevisiae and $11.2 \%$ for S. pombe) and L. major (9.6 \%) (Fig. 2a; see Additional file 4 for a complete overview of all RBDs in each organism). $T$. cruzii and $T$. gondii have intermediate levels of candidate mRBPs (7.4-7.9 \%), while candidate mRBP levels in T. brucei and all three multicellular organisms analyzed here are much lower (range 4.2-6.7 \%). Interestingly, these last four organisms have welldocumented functional RNA interference (RNAi) machinery to regulate transcript abundance. With the exception of $S$. pombe, all organisms with high to intermediate levels of candidate mRBPs do not encode functional RNAi machinery, suggesting that a larger number of mRBPs may compensate for the lack of an RNAi pathway to control post-transcriptional gene expression. In agreement, the Piwi Argonaute Zwille (PAZ) and Piwi domains, found in proteins involved in $\mathrm{RNAi}$, are absent or present at very low levels in the RNAi-negative organisms $P$. falciparum, P. vivax, T. cruzii, L. major, and S. cerevisiae (Additional file 3: Figure S2). It has to be noted that $T$. gondii does encode homologs of RNAi effector proteins Dicer, Argonaute, and RNA-dependent RNA polymerase that seem to produce miRNAs [36, 37], but experiments using double-stranded RNA for the downregulation of genes have not been uniformly successful [38].

To identify functional differences in RNA metabolism between organisms, the mRBDs were clustered based on the relative domain abundance among all 11 species (Fig. 2b). Each cluster was analyzed for enrichment of 


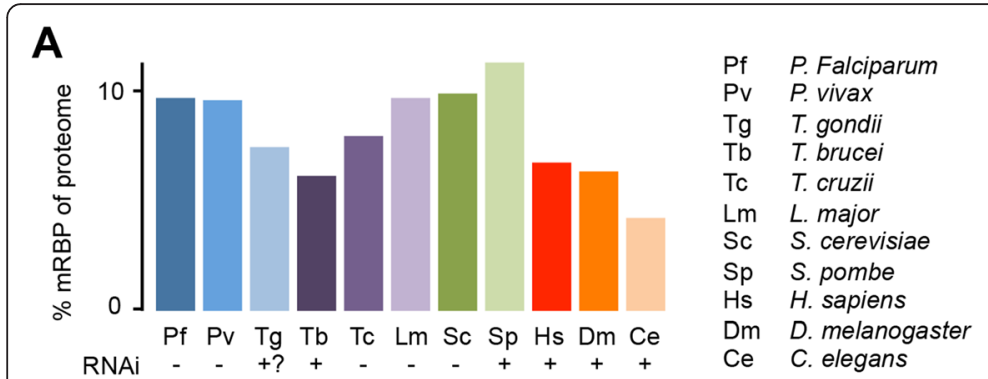

B

Pf Pv Tg Tb Tc Lm Sc Sp Hs Dm Ce
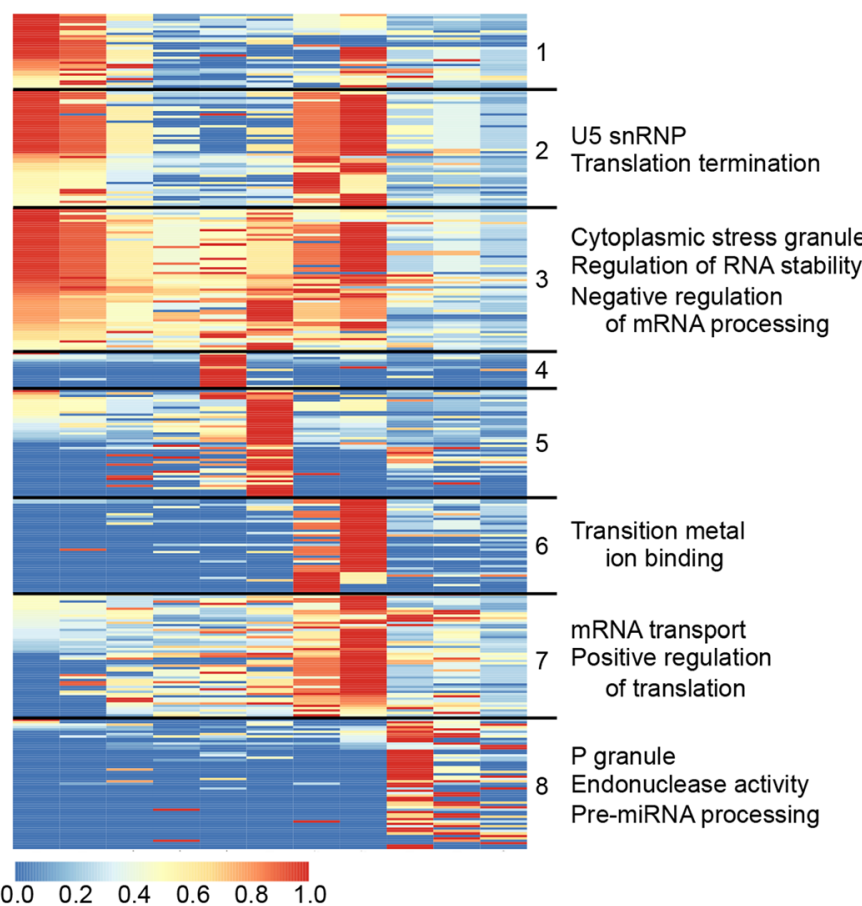

Transition metal ion binding

mRNA transport

Positive regulation of translation

P granule

Endonuclease activity

Pre-miRNA processing

$\begin{array}{llllll}0.0 & 0.2 & 0.4 & 0.6 & 0.8 & 1.0\end{array}$
C

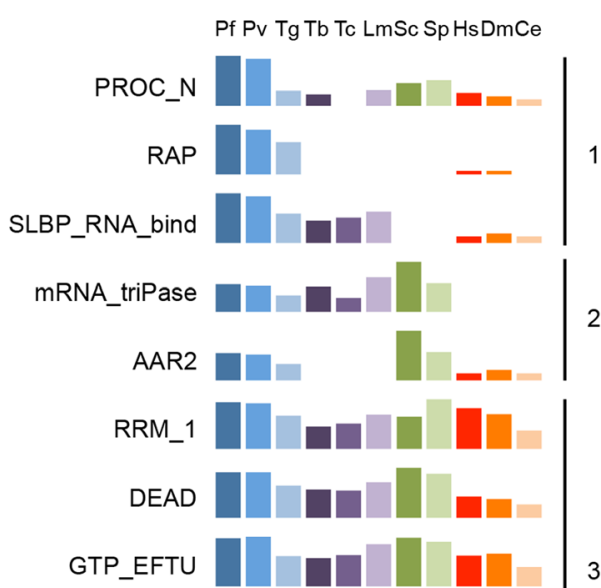

RNA_helicase

D

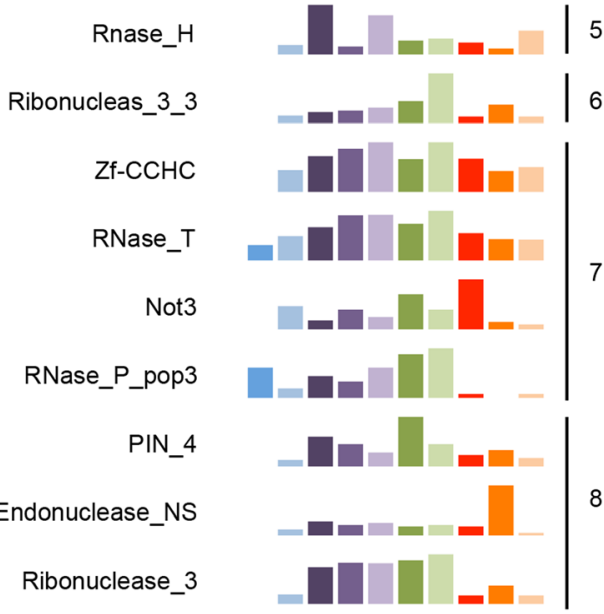

Fig. 2 Relative abundance of mRNA-binding domains in P. falciparum in comparison to other eukaryotes. a Percentage of proteins in the full proteome that contain an mRNA-binding domain ( $m R B D)$. Abbreviations are listed on the right. The presence $(+)$ or absence $(-)$ of RNA interference machinery is indicated at the bottom. $\mathbf{b}$ k-means clustering of mRBDs based on relative abundance among all 11 organisms. The mRBD frequency in an organism was first normalized by proteome size and then scaled to the mRBD frequency in the organism with the highest relative abundance of that mRBD, which was given an arbitrary abundance value of 1. For clusters with unique enriched Gene Ontology (GO) terms associated with the Pfam domains (false discovery rate, FDR $<0.01$ ), a subset of these terms is shown on the right. See Additional file 4 for the full data set. c Selection of mRBDs that are relatively enriched in $P$. falciparum as compared to all or select groups of other eukaryotes. The cluster that these mRBDs fall into is indicated on the right. d Selection of mRBDs that are relatively depleted in P. falciparum as compared to all or select groups of other eukaryotes

Gene Ontology (GO) terms associated with the Pfam domains. Clusters $1-3$ contain mRBDs that are relatively abundant in Plasmodium species, of which the domains in cluster 1 are almost exclusively enriched in Plasmodium. The domains in cluster 2 are also relatively abundant in Saccharomyces spp., and the domains in cluster 3 are most highly abundant in Plasmodium and Saccharomyces, but are also present in other unicellular organisms (Fig. 2b). These clusters show enrichment for GO terms associated with splicing and RNA stability (Fig. 2b and Additional file 4), and they contain several common RBDs, such as RRMs [18], DEAD, and GTP_EFTU domains. In addition, cluster 1 harbors the PROC_N domain, which is found in pre-mRNA splicing factors of the PRO8 family, and cluster 2 contains the AAR2 domain, most likely also involved in pre-mRNA splicing (Fig. 2c). Examples of other domains that are enriched in $P$. falciparum as well as in other unicellular organisms are RNA_helicase, MKT1_C, MKT1_N, and mRNA_triPase. Finally, the RAP domain (RNA-binding domain abundant in Apicomplexans) is almost exclusively found in apicomplexan parasites [39] (Fig. 2c). Fifteen RAP proteins have been annotated in the $P$. falciparum genome, with six additional proteins containing a RAP domain identified here. The function of 
these proteins has yet to be discovered. A total of 90 proteins contain RBDs that are uniquely abundant in Plasmodium species (cluster 1). These proteins show various patterns of gene expression throughout the parasite life cycle, with some being most highly expressed during the IDC, while others are expressed in gametocytes or ookinetes (Additional file 3: Figure S3).

Clusters 4-8 contain mRBDs that are relatively depleted in Plasmodium species as compared to one or multiple other organisms. These clusters show enrichment for GO terms associated with mRNA transport and RNA degradation. In addition to several zinc finger domains, many RNase domains (RNase_T, Endonuclease_NS, Ribonuclease_3, RNase_H, Ribonucleas_3_3, RNase_P_pop3), the PIN_4 domain found in proteins involved in non-sense mediated decay, and the Not3 domain found in the CCR4-NOT degradation complex are found at low abundance or are completely absent in Plasmodium (Fig. 2d). This could point towards the existence of highly divergent and parasite-specific RNA degradation pathways. Interestingly, T. cruzii (cluster 4), L. major (cluster 5), Saccharomyces spp. (clusters 6 and 7), and H. sapiens (cluster 8) also show enrichment for several RBDs as compared to other organisms (Additional file 3: Figure S4), suggesting that these organisms have also developed certain speciesspecific RNA-related mechanisms.

\section{Experimental identification of RNA-binding proteins}

To validate our in silico identification of mRBPs and to determine which mRBPs may specifically be involved in mRNA metabolism during the IDC, we next performed an experiment designed to capture the global mRNA interactome, similar to published studies on yeast, worm, fly, and human cells [40-45]. Parasite cultures at the trophozoite or schizont stage were irradiated in duplicate with UV light at $254 \mathrm{~nm}$ to preserve interactions between proteins and nucleic acids. While the integrity of RNA is somewhat decreased as a result of UV treatment (Additional file 3: Figure S5), optimization experiments showed that long UV exposure times are necessary to obtain sufficient crosslinking between RNA and proteins (data not shown). After lysis under denaturing conditions, protein-mRNA complexes were isolated using oligo $d(T)$ beads, followed by stringent washes with decreasing concentrations of salt and detergent (Fig. 3a). Under these conditions, we observed a depletion of the non-RNA interacting protein histone $\mathrm{H} 3$ (Fig. 3b) as well as $18 \mathrm{~S}$ ribosomal RNA, and an enrichment of known mRNA targets of PfSR1 and PfAlba1, mRBPs that are involved in post-transcriptional regulation during the IDC (Fig. 3c). As a negative control, we included a sample that was first UV-crosslinked and then digested with RNases before the pull-down of protein-mRNA complexes (XL-R).
Proteins were eluted by digestion of mRNA with MNase and analyzed using multidimensional protein identification technology (MudPIT). By comparing capture samples to XL-R control samples, we identified a total of 199 proteins that are likely to directly or indirectly interact with mRNA (Additional file 5). These proteins were detected in at least two out of four independent samples that were analyzed (two replicates performed at the trophozoite and schizont stages, see Additional file 3: Figure S6A and Figure S6B) at $\geq 2$-fold higher abundance in the capture sample as compared to the control sample. The captured mRBPs showed strong enrichment for GO terms associated with RNA homeostasis (Fig. 3d; see Additional file 6 for a full list of enriched GO terms). Another 514 proteins were enriched in only one capture experiment. A total of 81 candidate mRBPs detected in at least two independent capture experiments were identified in our computational search for mRBPs, while another 81 computationally identified $\mathrm{mRBP}$ candidates were captured in only one experiment. Together, the 162 candidate mRBPs that were captured at least once validate $41.8 \%$ of the mRBP candidates identified in our HMM search (Fig. 3e) and represent $23 \%$ of all experimentally detected candidate mRBPs (Fig. 3f).

Among the candidate mRBPs that were captured in at least two experiments $(n=199)$, the fraction of proteins interacting with mRNA or DNA/RNA was 6.5-fold enriched as compared to proteins that were depleted in the capture versus the RNase control samples (Additional file 3: Figure $\mathrm{S} 6 \mathrm{C}$ ). This enrichment was highest in the group of proteins that were identified with most confidence (i.e., enriched in all four experiments) and decreased with the number of experiments in which a protein was identified (Additional file 3: Figure S6C). In addition, the fraction of proteins without an $\mathrm{mRBD}$ was inversely correlated with the number of times a protein was identified (Additional file 3: Figure S6D). As compared to the proteome-wide abundance, significant enrichment was observed for the highly abundant RRM and DEAD domains, as well as for 14 less abundant domains, including LSm, RNA_bind, SM_ATX, zf-CCCH, KH_3, KH_4, and Alba $(p<0.05,5 \%$ FDR; Fig. 3g, Additional file 6).

The relative abundance of candidate mRBPs at the two different stages of the parasite IDC was strongly correlated (Spearman $R=0.67$; Fig. $3 \mathrm{~h}$ ), resulting in a significant overlap between the mRNA-bound proteomes at the trophozoite and schizont stages $(n=155, p<0.0001$; Additional file 3: Figure S6E). Furthermore, mRBPs with higher relative abundance levels were more likely to be detected in three or more experiments (Fig. 3h). Interestingly, five out of 11 candidate mRBPs that were detected at relatively high abundance (dNSAF >0.01) showed a higher enrichment at the schizont stage than 


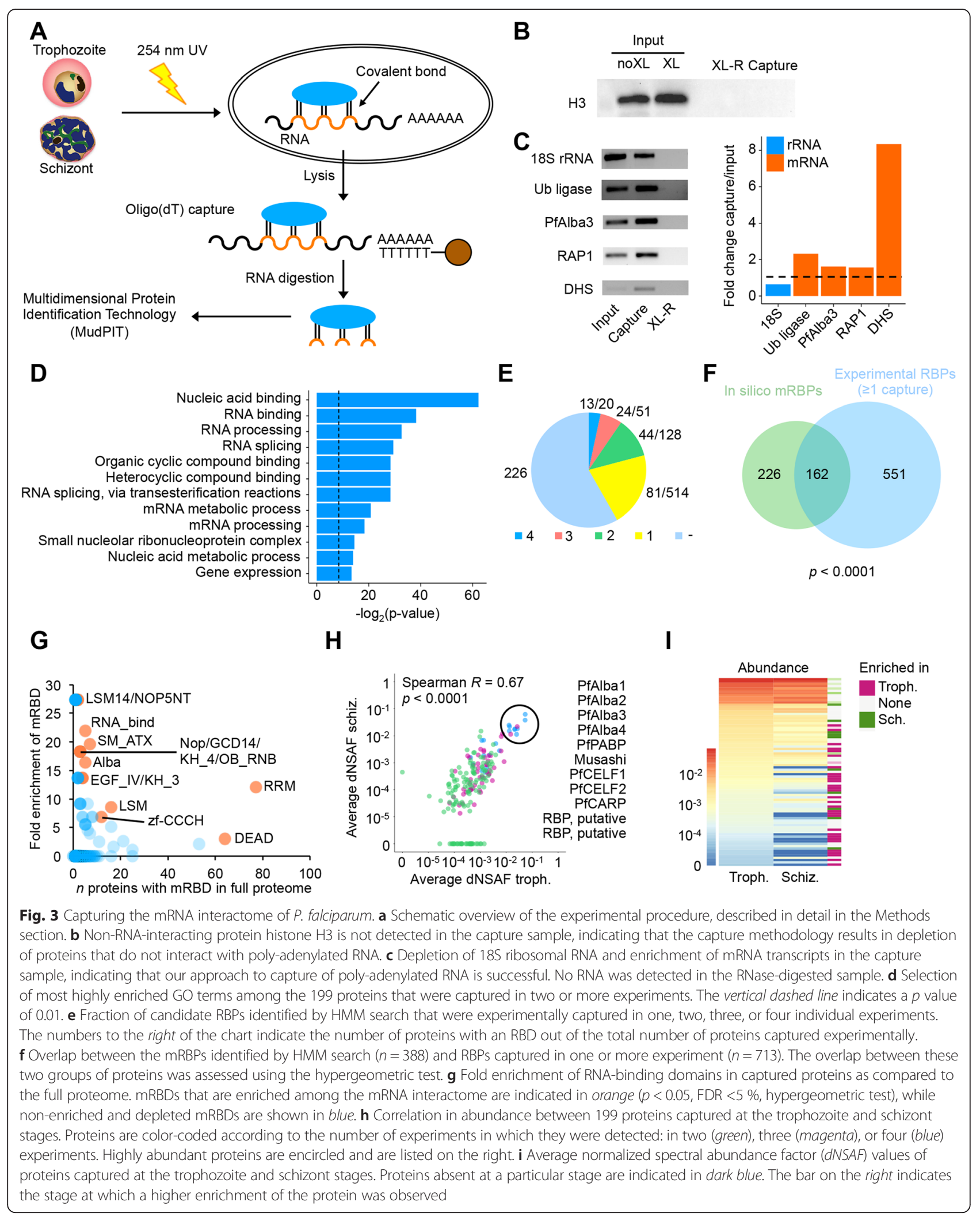


the trophozoite stage, including the four PfAlba proteins (Fig. 3i and Additional file 5), while proteins that show selective enrichment at the trophozoite stage are much less abundant (dNSAF <0.003). These results may indicate that the function of these highly abundant proteins may be particularly important at the schizont stage.

To define a stringent set of mRBPs active in the asexual stages of $P$. falciparum, we applied a conservative filter for differential protein abundance in the capture versus control data using the combined spectral counts from all four experiments (see Methods). In addition, we compared the spectral counts in our capture experiments with spectral counts from an existing P. falciparum mass spectrometry data set [46] to filter out any highly abundant proteins that could be contaminants. A total of 64 proteins meet both of these criteria (Additional file 5), of which the top $20 \mathrm{mRBPs}$ detected with high confidence are listed in Table 1. Among these 64 mRBPs are many of the known translational regulators in $P$. falciparum:
PfAlba1, PfCELF2 (formerly annotated as Bruno or HoBo), Musashi (HoMu), and CITH, as well as PfAlba2, 3, and 4, PfCELF1, and DOZI (Additional file 5). PfCELF1 is a recently identified member of the Bruno/CELF protein family with verified RNA-binding activity in $P$. falciparum [35]. DOZI has a known role in translational control in gametocytes. Together with a recent study showing a granular pattern of DOZI in the cytoplasm of asexual stage parasites [47], our results suggest that DOZI may also be involved in post-transcriptional mechanisms similar to those in gametocytes during the IDC. In addition, the list includes the highly expressed (top $1 \%$ at the ring stage [34]) putative exporter of spliced mRNA PF3D7_1006800, CELF-like protein PF3D7_0823200, and another protein with CELF homology (PF3D7_1236100, clustered-asparagine-rich protein [30]), and further includes eight putative RBPs, one RAP protein, and 16 proteins with unknown function (Additional file 5). Finally, known mRBPs PUF1, PfSR1, and PfCAF1 were

Table 1 Candidate mRNA-binding proteins captured with high confidence in trophozoite- and schizont-stage parasites

\begin{tabular}{|c|c|c|c|c|c|c|c|c|c|}
\hline \multirow[t]{2}{*}{ Locus } & \multirow[t]{2}{*}{ Description } & \multirow{2}{*}{$\begin{array}{l}\text { Average } \\
\text { spectra } \\
\text { detected }\end{array}$} & \multicolumn{4}{|c|}{ Fold enrichment $^{a}$} & \multirow{2}{*}{$\begin{array}{l}\text { Pfam RNA-binding } \\
\text { domain }\end{array}$} & \multirow{2}{*}{$\begin{array}{l}\text { QSPEC } \\
p \text { value }^{\mathrm{b}}\end{array}$} & \multirow{2}{*}{$\begin{array}{l}\text { Chi-square } \\
p \text { value }^{c}\end{array}$} \\
\hline & & & Troph. 1 & Troph. 2 & Schizont 1 & Schizont 2 & & & \\
\hline PF3D7_1006800 & RBP, putative & 284 & 10.3 & 23.7 & 13.2 & 6.2 & RRM & 0 & $8.6 \mathrm{E}-144$ \\
\hline PF3D7_1409800 & PfCELF2 (formerly Bruno) & 237 & 4.7 & 7.4 & 8.1 & 6.0 & RRM, RNA_bind & 0 & $2.3 \mathrm{E}-126$ \\
\hline PF3D7_0916700 & Musashi (HoMu) & 187 & 11.4 & 5.5 & 37.0 & 4.0 & RRM & 0 & 1.7E-95 \\
\hline PF3D7_1359400 & PfCELF1 & 176 & 4.8 & 11.7 & 8.5 & 9.9 & RRM, RNA_bind & 0 & $2.3 \mathrm{E}-85$ \\
\hline PF3D7_0929200 & RBP, putative & 179 & 6.7 & 3.5 & 5.7 & 1.4 & RRM & 0 & $2.8 \mathrm{E}-74$ \\
\hline PF3D7_1236100 & PfCARP & 151 & 6.9 & 1.9 & 13.0 & 2.8 & RRM, RNA_bind & 0 & $5.4 \mathrm{E}-52$ \\
\hline PF3D7_0105200 & RAP protein, putative & 53 & 2.8 & 2.8 & 24.5 & 13.2 & RAP & 0 & $7.9 \mathrm{E}-26$ \\
\hline PF3D7_1346300 & PfAlba2 & 92 & 30.7 & 2.6 & 63.7 & 53.0 & Alba & 0 & $8.6 \mathrm{E}-26$ \\
\hline PF3D7_1021900 & Conserved protein & 113 & 2.1 & 2.0 & 2.6 & 3.9 & RNA_GG_bind & 0 & 9.7E-25 \\
\hline PF3D7_0823200 & RBP, putative & 112 & 1.8 & 1.9 & 5.4 & 1.5 & $\begin{array}{l}\text { RRM, RNA_bind, } \\
\text { DUF1866 }\end{array}$ & 0 & $2.0 \mathrm{E}-24$ \\
\hline PF3D7_1105800 & Conserved protein & 53 & 4.0 & 0.6 & 5.6 & 13.2 & - & 0 & $8.8 \mathrm{E}-23$ \\
\hline PF3D7_1006200 & PfAlba3 & 131 & 4.4 & 5.1 & 12.8 & 11.6 & Alba & 0 & $2.8 \mathrm{E}-18$ \\
\hline PF3D7_0703500 & $\begin{array}{l}\text { Erythrocyte membrane-associated } \\
\text { antigen }\end{array}$ & 80 & 0.9 & 2.9 & 5.7 & 4.4 & DEAD & 0 & 4.4E-18 \\
\hline PF3D7_0629400 & RBP, putative & 36 & Infinity & 7.0 & Infinity & 0 & RRM & 0 & $1.1 \mathrm{E}-14$ \\
\hline PF3D7_1107300 & PfPAIP1 & 73 & 1.2 & 3.2 & 1.9 & 4.4 & - & 0 & $1.2 \mathrm{E}-13$ \\
\hline PF3D7_1474900 & $\mathrm{CITH}$ & 31 & 3.1 & 6.0 & 4.8 & 13.2 & $\begin{array}{l}\text { LSM14, FDF, } \\
\text { SM_ATX }\end{array}$ & 0 & 4.0E-13 \\
\hline PF3D7_1118200 & Heat shock protein 90 & 41 & 3.1 & 4.9 & 8.8 & 3.6 & - & 0 & $3.4 \mathrm{E}-09$ \\
\hline PF3D7_0810600 & RNA helicase, putative & 52 & 3.6 & 2.9 & 4.2 & 0 & DEAD & 0 & $1.5 \mathrm{E}-07$ \\
\hline PF3D7_1347500 & PfAlba4 & 103 & 4.5 & 4.7 & 6.3 & 7.4 & - & 0 & $2.1 \mathrm{E}-06$ \\
\hline PF3D7_1330800 & Conserved protein & 37 & 8.4 & 1.8 & Infinity & 0 & RRM & 0 & $6.8 \mathrm{E}-04$ \\
\hline
\end{tabular}

aEnrichment of proteins in mRNA-interactome capture sample as compared to the corresponding RNase-treated control sample

${ }^{\mathrm{b}}$ Analysis of differential protein abundance in the capture versus control data using the combined spectral counts from all four experiments. Reported $p$ values are FDR-corrected (5\% [80])

'Analysis of protein abundance in the capture data compared to an existing $P$. falciparum mass spectrometry data set [46] to assess the likelihood of contamination. Reported $p$ values are FDR-corrected using the Benjamini-Hochberg method (5\%)

Troph. trophozoite 
detected in one capture experiment but did not pass the stringent filters.

\section{RNA-binding proteins involved in translation}

To identify RBPs that may play a regulatory role during the process of translation, we determined which proteins are associated with polysomes in the IDC. In duplicate experiments, ribosomes from lysates of red blood cells infected with ring-, trophozoite-, or schizont-stage parasites were separated over a sucrose gradient (Fig. 4a). Proteins present in the polysomal fractions were subsequently analyzed using MudPIT, yielding a total of 126 proteins that were detected with $\geq 2$-fold higher abundance in polysome fractions than in cytoplasmic fractions of parasites of the same stage and that were detected in duplicate experiments. None of these proteins were detected after disruption of polysomes by EDTA treatment (data not shown), suggesting that they are truly associated with polysomes and not merely cosedimenting in polysome fractions. Overall, replicate experiments showed a strong correlation for detected protein abundance (Spearman $R=0.86$; Fig. $4 \mathrm{~b}$ ). We also observed overlaps between $45-88 \%$ for non-ribosomal proteins detected at the same IDC stage in replicate experiments (Additional file 3: Figure S7).

Between $93.7-95.8 \%$ of P. falciparum proteins identified in the polysomal fractions were ribosomal proteins ( $n=75$; Fig. $4 \mathrm{c}$ ), which were highly enriched compared to cytoplasmic fractions (on average 13.6-fold enrichment). The largest fraction of non-ribosomal proteins associated with polysomes consisted of known or predicted mRNA-binding proteins $(2.7-4.8 \%$, Fig. 4c).

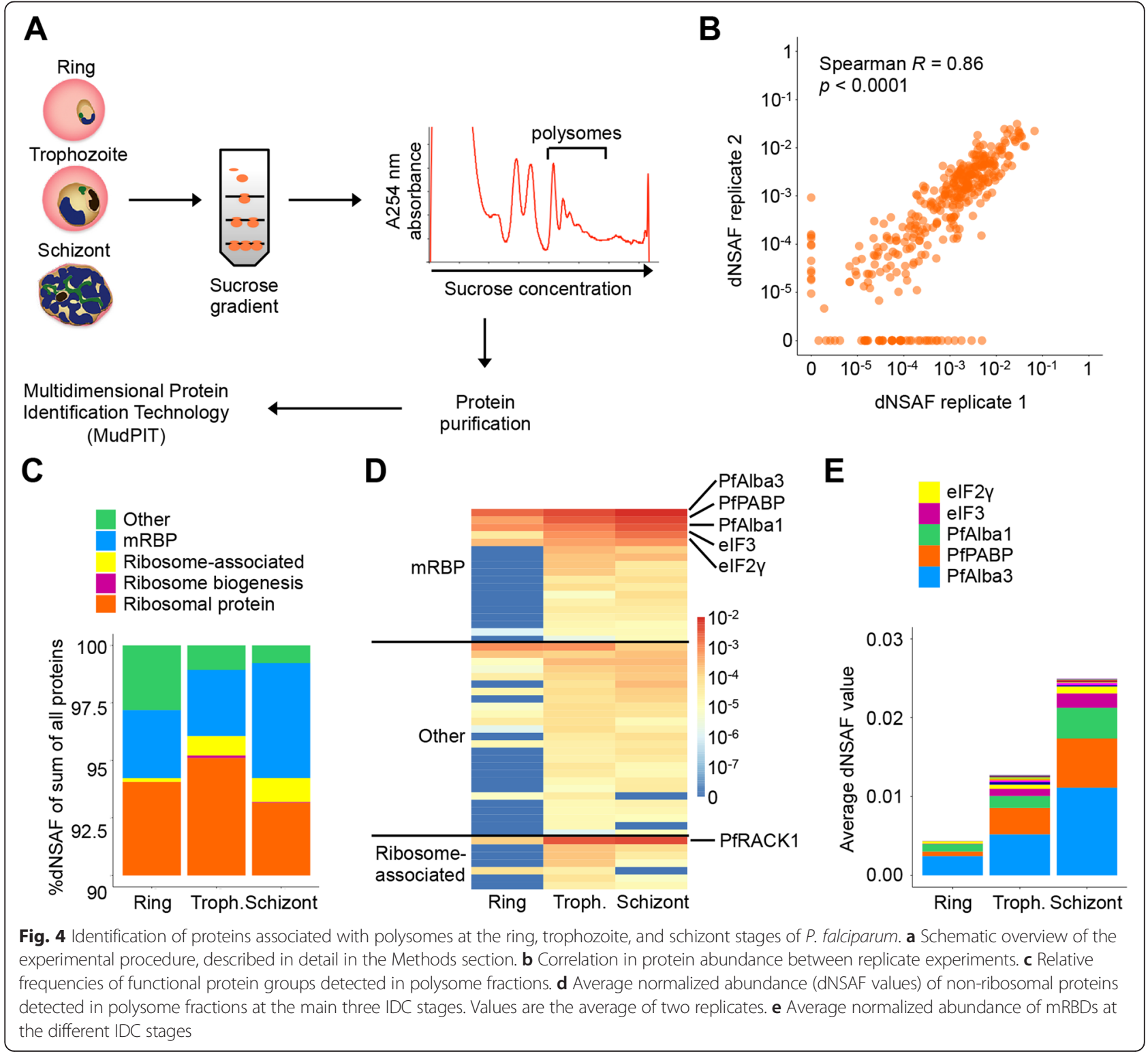


Several proteins known to be involved in translation, such as subunits of eukaryotic initiation factors (eIF) 2 and 3 and polyadenylate-binding protein (PfPABP), were highly abundant (dNSAF $>10^{-4}$ ), as well as the DNA/ RNA-binding proteins PfAlba1 and PfAlba3 (Table 2). Other known or predicted mRBPs were observed at lower abundance, including PfCAF1, the RRM domaincontaining putative RNA-binding protein PF3D7_0629400, and $\mathrm{CCCH}$ zinc finger proteins PF3D7_0525000 and PF3D7_0906600 (Table 2). CCCH-type zinc finger proteins are commonly involved in regulating mRNA decay and translation rates and are relatively abundant in $P$. falciparum [11]. Another CAF protein (PfCAF40; PF3D7_0507600) and a NOT family member (both part of the CCR4-NOT complex) were also identified, as well as putative ribonuclease PF3D7_0615400. Finally, we detected several proteins known to be associated with ribosomes or involved in ribosome biogenesis, as well as 19 conserved Plasmodium proteins with unknown function, of which only one contained an RBD (IF4E, found in the eukaryotic translation initiation factor 4E family; Additional file 7). Interestingly, the ribosome-associated protein receptor for activated C-kinase 1 (PfRACK1; PF3D7_0826700) was detected in five out of six polysome preparations with relatively high abundance (Fig. 4d), while it was not detected in cytoplasmic fractions. The average normalized abundance ratio between PfRACK1 and ribosomal proteins was 0.65:1 across all six experiments. Recent cryo-electron microscopy studies reported the unusual absence of PfRACK1 from the $P$. falciparum ribosome and suggested that this protein may be largely ribosome-unbound in the parasite $[48,49]$. However, our results indicate that PfRACK1 is mostly associated with ribosomes, although its association may easily be disrupted by experimental procedures.

Overall, only a small number of RBPs were found to be associated with polysomes. This could reflect restricted regulation of gene expression during the process of translation, but it could also be the result of limited sensitivity of the mass spectrometry analysis. Most polysome-associated proteins were detected at the trophozoite and schizont stages (Fig. 4d), consistent with higher levels of translation at these IDC stages. Of the mRBPs, only PfAlba1, PfAlba3, PfPBAP, and eIF2 $\gamma$ were present constitutively (Fig. 4d and Additional file 3: Figure S8). On average, the abundance of RBPs in the polysome fractions was highest at the schizont stage (Fig. 4e), suggesting that many of these proteins are involved in timing the moment of translation of proteins expressed later in the IDC, similar to PfAlba1 and PfCAF1 [27, 28].

\section{Discussion}

Evidence is accumulating that post-transcriptional mechanisms play important roles in regulating gene expression during various stages of $P$. falciparum's life cycle, including the intraerythrocytic developmental cycle $[14,15,24,25,27,28]$. To better understand these regulatory processes, it is essential to know which RNAbinding proteins (RBPs) are involved in RNA metabolism in the parasite. While many RBPs are annotated as

Table 2 mRNA-binding proteins associated with polysome fractions during the IDC

\begin{tabular}{lll}
\hline Locus & Description & Pfam RNA-binding domain \\
\hline PF3D7_0811300 & PfCAF1 & CAF1 \\
PF3D7_0507600 & PfCAF40 & IF4E \\
PF3D7_0111800 & Conserved Plasmodium protein, unknown function & Alba, Rpp20 \\
PF3D7_0814200 & PfAlba1 & Alba \\
PF3D7_1006200 & PfAlba3 & EIF_2_alpha, S1, EXOSC1 \\
PF3D7_0728000 & elF2 alpha subunit & GTP_EFTU, elF2_C, GTP_EFTU_D2, MMR_HSR1 \\
PF3D7_1410600 & elF2 gamma subunit & - \\
PF3D7_0716800 & elF3 subunit I & elF2A, RRM \\
PF3D7_0517700 & elF3 subunit B & Not1 \\
PF3D7_1417200 & NOT family protein, putative & - \\
PF3D7_1107300 & PfPAlP1 & RRM, PABP \\
PF3D7_1224300 & PfPABP & RNB, OB_RNB \\
PF3D7_0615400 & Ribonuclease, putative & RRM \\
PF3D7_0629400 & RNA-binding protein, putative & Nol1_Nop2_Fmu, Methytransf_31, FtsJ \\
PF3D7_1129400 & RNA methyltransferase, putative & RRM \\
PF3D7_0503300 & Ser/Arg-rich splicing factor, putative & zf_CCCH \\
PF3D7_0525000 & CCCH zinc finger protein, putative & - \\
PF3D7_0906600 & CCCH zinc finger protein, putative & \\
\hline
\end{tabular}


such in the well-curated Plasmodium database (PlasmoDB, www.plasmodb.org), a systematic overview of $P$. falciparum RBPs has been lacking. The data presented here give the most complete overview of RBPs in the malaria parasite $P$. falciparum to date.

By searching the $P$. falciparum proteome using a large array of Pfam domains involved in all aspects of RNA metabolism, we have attempted to capture every single RBP. Since the P. falciparum genome is relatively distant from that of more classical model organisms, we used relatively non-stringent parameters for the HMM search to increase our chances of identifying RBPs with weakly homologous RNA-binding domains (RBDs). For the small number of Pfam domains for which it was readily apparent that our threshold for inclusion resulted in false positives, we used more stringent inclusion criteria (see Methods). In addition, we have attempted to account for false positive hits by narrowing down our initial broad search to proteins that specifically interact with mRNA, using information from the current genome annotation. Our results are in good agreement with a recent bioinformatics analysis that focused on a limited set of RBPs with relatively common or well-characterized RBDs [30] and catalogs many additional RBPs that to our knowledge have not previously been indexed in this fashion. Conflicts in the lists of RBPs retrieved in these two studies could be the result of different search approaches: Reddy et al. [30] used HMM profiles built from RBPs that were identified in a text-based search of PlasmoDB, while this study scanned the genome using Pfam domains. Further experimental work will be necessary to validate the function of these computationally identified RBPs in RNA biology.

In an unbiased comparison with other eukaryotic organisms, we observed that $P$. falciparum is among the species that encode a relatively large number of mRNAbinding proteins (mRBPs). Some of these mRBPs contain a domain (e.g., RAP) that is found almost exclusively in apicomplexan parasites (Fig. 2b). While the exact function of these proteins will have to be validated at the molecular level, this finding in all likelihood reflects the importance of RNA metabolism for parasite biology and is in agreement with the presumed role of posttranscriptional mechanisms of gene regulation, in particular at the level of mRNA stability and degradation.

The coordinated post-transcriptional control of ookinetespecific transcripts in the female gametocyte has been well documented and involves the stabilization of transcripts in ribonucleoprotein complexes with regulators such as DOZI and CITH [23-25]. Our data strongly suggest that these regulators also play important roles during the IDC. In addition, other post-transcriptional regulators, including PfSR1 and PfAlba1, have recently been identified to control subsets of genes during the IDC [27, 28]. This coordinated regulation of functionally related genes is analogous to gene regulation in trypanosomes. Transcription in T. brucei and T. cruzii is polycistronic, and extensive regulation of gene expression occurs at the posttranscriptional level (reviewed in [50]). Functionally related genes show coordinated expression throughout the cell cycle and during differentiation into other parasitic stages [51]. These regulons are presumably controlled by RBPs that recognize regulatory elements in the untranslated regions of mRNA, and the identification of factors involved in these regulatory processes has brought rapid progress to understanding trypanosome biology (see reviews [52-54] and references therein). Further validation and characterization of the RBPs identified in this study is likely to bring similar advances to the malaria field. The disruption of genes encoding RBPs relatively often confers a phenotype of severely attenuated growth [55]. A recent antimalarial drug screen identified the compound DDD107498 as an inhibitor of P. falciparum translation elongation factor 2 (eEF2) with activity against multiple stages of the parasite life cycle [56]. This discovery shows the importance of translation for parasite survival and indicates that proteins involved in RNA metabolism, and in particular in post-transcriptional and translational gene regulation, may provide excellent targets for novel antimalarial drugs.

Out of a total of 388 proteins that contain an mRNAbinding domain and are thus likely to be involved in mRNA metabolism in the parasite, 162 proteins (42\%) were experimentally confirmed in our mRNA-interactome capture experiments. Proteins that were not identified in our mRNA-interactome capture experiments may act during other stages of the parasite's complex life cycle, may be only transiently expressed, or may have low expression levels and are therefore difficult to detect by mass spectrometry. Mass spectrometry is known to be biased towards highly abundant proteins. Even though the correlation between spectral counts in our data and RNA-Seq expression levels is weak (Pearson $R=0.32$ and 0.24 at the trophozoite and schizont stages, respectively), there is indeed a trend towards a more frequent detection of proteins with higher expression levels (Additional file 3: Figure S9). In addition, we may have missed the detection of mRBPs as a result of our experimental approach for the mRNA-interactome capture experiments. In this study, we used conventional UV-crosslinking ( $\mathrm{CCL}$ ) to induce covalent bonds between RNA and interacting proteins. An alternative strategy, called photo-activatable crosslinking or PAR-CL, is to supply thiol-labeled uridine to cells, which is then incorporated into nascent RNA and can efficiently be crosslinked to protein by $365 \mathrm{~nm}$ UV light irradiation $[41,44]$. For $P$. falciparum, this strategy requires the use of a transgenic parasite strain that is capable of salvaging pyrimidines from its environment. 
Despite differences in crosslinking chemistries, the overlap in mRBPs captured from human cells using cCL or PAR-CL is large (two-thirds or more) [41, 44]. Nevertheless, it would be interesting to compare the results of both strategies to explore the full mRNA-bound proteome of $P$. falciparum. Finally, as a result of RNA degradation due to UV exposure and subsequent poly-A selection, our capture data may be biased towards proteins that bind at the 3' end of mRNA transcripts and be less likely to detect proteins that bind at the $5^{\prime}$ end.

It is known that UV-crosslinking experiments often yield many false positives as a result of background from proteins that are covalently crosslinked to RNA in a non-specific manner. Recent efforts have been made to characterize and correct for this type of background noise in PAR-CL data [57] and to optimize the experimental procedures for CLIP-Seq experiments [58]. In addition, we noticed that UV-crosslinking of $P$. falciparum parasites results in increased non-specific protein pull-down during the capture procedure, which can increase the number of false positives. We have controlled for this phenomenon by performing UV-crosslinking followed by RNase digestion of the control sample, instead of using a non-UV-crosslinked control as is more common for these types of experiment [40, 41]. To provide additional confidence and supply a means to filter false positives from our data set, we have performed two additional stringent statistical tests based on (1) protein enrichment in capture versus control data and (2) removal of highly abundant proteins that could be contaminants. Applying these two additional filters resulted in a final list of 64 mRBPs experimentally captured with high confidence, which makes an excellent starting point for further exploration of the $P$. falciparum mRNAbound proteome. We stress that this is a very conservative list of mRBP candidates that may not include all true hits from our experimental capture approach.

Several of the proteins that were found to be essential for normal IDC development in the genetic screen by Balu et al. [55] were captured in our mRNA interactome, including PfCAF1 (enriched in one mRNA-interactome capture experiment) and the putative RNA-binding proteins PF3D7_1360100 (enriched in three capture experiments) and PF3D7_0812500 (enriched in one capture experiment; Additional file 5 ). These latter two proteins were also identified as important interacting partners, connecting interaction networks of proteins involved in RNA metabolism and protein folding and trafficking [59]. In addition, the results of our experimental strategies to validate the role of RBPs during the IDC suggest an important function of PfAlba1-4 proteins in posttranscriptional gene regulation in P. falciparum. All four PfAlba proteins were highly enriched in the mRNAinteractome capture experiment, and PfAlba1 and
PfAlba3 were also found to be associated with polysomes. PfAlba1 is a known regulator of translation, in particular for genes involved in merozoite egress and invasion [28], although the exact mechanism by which the protein acts remains to be established. The function of the other PfAlba proteins in post-transcriptional regulation is less well determined. During the trophozoite and schizont stages, PfAlba1-4 are localized in granules that could represent ribonucleoprotein complexes [60], suggestive of a role in regulating mRNA stability and degradation. Additional mechanistic insight into how these proteins function is still missing and warrants further investigations into the role of these proteins in the parasite in post-transcriptional and translational gene regulation. Interestingly, the recent identification of two additional PfAlba proteins based on the presence of an Alba domain (PfAlba5 and PfAlba6) [30] was confirmed in our HMM search. Of these two new members of the Alba family, PfAlba6 shares only limited sequence identity with the other five PfAlba proteins. Neither PfAlba5 nor PfAlba6 were identified in our mRNA-interactome capture experiments and have relatively low expression levels during the IDC, gametocyte, and ookinete stages [34], suggesting that if these are indeed bona fide PfAlba proteins, they may function in other stages of the parasite's life cycle.

Three of the polysome-associated proteins identified in this study can also be found in stress granules and P-bodies, including members of the CCR4-NOT complex (PfCAF1, PfCAF40, and PfNOTx), as well as eukaryotic translation initiation factors and the PfAlba proteins $[25,61,62]$. Such ribonucleoprotein complexes are involved in translational regulation and mRNA decay (reviewed in [63]) and have an established role in transcript stabilization in female gametocytes [24, 25]. However, the CCR4-NOT complex can also be associated with transcripts in the cytoplasm and during translation (reviewed in [64]) and is, for example, involved in translational repression of transcripts that cause ribosome stalling [65]. In addition, many of the other components of P-bodies or stress granules (such as DOZI and CITH in $P$. falciparum) were not detected. Thus, although we cannot completely eliminate the hypothesis that some RNA granules may have co-sedimented with the polysome fractions, the proteins that we identified here are more likely to be associated with polysomes than with other structures in the cell.

\section{Conclusion}

This study presents the most complete resource of RNA-binding proteins in P. falciparum to date. We have computationally identified RNA-binding proteins based on the presence of RNA-binding domains and further classified these proteins into functional categories. 
Furthermore, we provide experimental evidence for the role of a subset of RBPs in mRNA homeostasis during the IDC, the stage responsible for disease in humans. The function of many RBPs is still unknown, and further characterization of RBPs important for parasite development is therefore likely to increase our understanding of parasite biology and to reveal excellent novel targets for drug discovery.

\section{Methods}

\section{HMM search}

Protein sequences were obtained from the following sources: PlasmoDB version 13.0 ( $P$. falciparum strain 3D7), PlasmoDB version 24.0 ( $P$. vivax strain Sal I), ToxoDB version 24.0 (T. gondii strain ME49), TriTrypDB version 24.0 ( $T$. brucei strain TREU927, T. cruzi strain CL Brener Esmeraldo-like, and L. major strain Friedlin), Saccharomyces Genome Database (S. cerevisiae strain S288C genome assembly R64-2-1 [66]), PomBase (S. pombe downloaded on 25 June 2015), and Ensembl release 80 [67] (H. sapiens genome assembly GRCh38.p2, C. elegans genome assembly WBcel235, and D. melanogaster genome assembly BDGP6). Protein sequences were searched for the presence of Pfam HMM profiles (Pfam version 27.0 [68]) using the function hmmscan of the HMMER software package [69] (version 3.1b1, release May 2013). Proteins containing any of 793 Pfam RNA-binding protein (RBP) domains [31] (for P. falciparum only) or $372 \mathrm{mRBP}$ domains (all other organisms) with an E-value below 0.01 were included in subsequent analyses (see Additional file 1). Six of the RBP domains used by Gerstberger et al. [31] are no longer listed in the Pfam database.

The resulting list of RBPs was manually curated. For Pfam domain eIF2A (PF08662), an E-value cutoff of 0.01 resulted in false positives in multiple organisms, in particular from proteins with a WD domain that are typically involved in signal transduction, transcription, and cell cycle control (Additional file 3: Figure S10). Therefore, a more stringent cutoff of $1 \mathrm{E}-15$ was used for this domain. The Bud13 (PF09736) domain yielded seven false positives in P. falciparum (all members of exported protein family 3) with E-values between 0.01 and 0.001, while the true hit (PF3D7_1246600) obtained an E-value of 2.10E-43. The cutoff for this Pfam domain was therefore lowered to 0.001. Similar discrepancies between HMM results and gene annotations were not observed for any of the other Pfam domains. Applying an E-value cutoff of 0.001 to all Pfam domains would result in the exclusion of a total of 63 proteins, including 16 known RBPs and 19 conserved proteins with unknown function, and was therefore considered too stringent.

Proteins containing DNA-binding zinc finger domains (KRAB, SCAN, BTB, zf-met, zf-C2 2 2, and zf-C2H2_jaz) were removed from the data set. For proteins with multiple isoforms, the isoform with the highest number of Pfam domains was selected. If multiple isoforms had equal numbers of domains, the longest isoform was chosen. For $P$. falciparum, genes with a gene annotation containing "RNA," "ribosomal," or "translation" were manually added to the list of candidate RBPs $(n=40)$, as well as genes with the Gene Ontology (GO) terms "RNA binding" (GO:0003723), "rRNA binding" (GO:0019843), or "tRNA binding" (GO:0000049) among the first three GO terms listed for that gene $(n=24)$. Nine of the genes added based on GO annotation had an RNA-related gene description (for example, PF3D7_0621900, signal recognition particle subunit SRP68), while the other 15 were genes with unknown function. It is possible that the current gene annotation is incorrect and that these genes were mislabeled as "RNA binding." Out of all 64 manually added genes, nine genes contained weak to very weak RBDs (median E-value $=0.041$ ), of which five were strongly related to the gene annotation. Diversification of these genes in P. falciparum may have precluded identification of these domains in our HMM search.

The type of molecule that the candidate RBP interacts with was determined based on existing annotations and known functions of homologs in other species. If this information was not available, the type of molecule was predicted based on the nature of the RNA-binding domain (RBD). Proteins for which no information was available were categorized as "non-RNA."

To calculate the percentage of sequences from groups of organisms in the HMM seed, the HMM seed file (Pfam version 27.0) was downloaded, filtered for the 372 mRNAbinding domains used in this study, and parsed for UniProt accession numbers. The source organism of each sequence was then retrieved using the retrieve/ID mapping tool on the UniProt website (http://www.uniprot.org/ uploadlists/) and matched to the corresponding Pfam domain. For each domain, the percentage of sequences derived from each group at the third level of the taxonomic lineage was determined.

In each organism, a variety of proteins that are unlikely to be involved in RNA metabolism were identified in the HMM search. However, manually curating these protein lists would introduce a bias, since not all genomes have been annotated to the same extent. Therefore, to make a fair comparison between organisms, we included all mRBD-containing proteins in our subsequent analysis, irrespective of their annotation. To correct for differences in genome size, RBD abundance was expressed as the number of RBDs per 10,000 genes. Pfam domains that were present in at least one out of 11 organisms $(n=353)$ were clustered based on their relative abundance across organisms using the $k$-means clustering algorithm with a maximum of 1000 iterations in R v2.7.0 [70]. Determination of the optimal number of 
clusters $(n=8)$ was guided by the percentage of variance that was captured by the clusters. We selected the smallest number of clusters for which an increase in the number of clusters did not capture at least an additional $2 \%$ of the variance (expressed as a within-group sum of squares). A heatmap of clustered Pfam domain abundance was generated using the pheatmap package in $R$ v2.7.0. Domain-centric GO analysis of Pfam domain clusters was performed using the web-based version of dcGO (http:// supfam.org/SUPERFAMILY/cgi-bin/dcenrichment.cgi) [71], with a collapsed subset of GO terms and a false discovery rate $(\mathrm{FDR})<0.01$.

\section{Gene expression analysis}

PlasmoDB has preprocessed all available RNA-Seq expression data sets using standardized pipelines to ensure comparability between data sets. Normalized RPKM gene expression data from seven stages of the $P$. falciparum life cycle [34] were downloaded from PlasmoDB v26. Notched box plots of expression values for various groups of proteins were generated using the ggplot2 package in $R$ v2.7.0. Differences in expression levels between groups of proteins were assessed using the Welch's unequal variances $t$ test. The heatmap of gene expression patterns for candidate RBPs with Plasmodium-specific RBDs was generated from $\mathrm{z}$-scored RPKM values using the pheatmap package in $\mathrm{R} v 2.7 .0$.

\section{Parasite cultures}

The P. falciparum strain 3D7 was cultured in human $\mathrm{O}^{+}$ erythrocytes at $5 \%$ hematocrit as previously described [72]. Cultures were synchronized twice at ring stage with $5 \%$ D-sorbitol treatments performed $8 \mathrm{~h}$ apart [73]. Cultures (8\% parasitemia in $5 \%$ hematocrit in a total volume of $25 \mathrm{ml}$ ) were harvested $48 \mathrm{~h}$ after the first sorbitol treatment (ring stage) and then $18 \mathrm{~h}$ (trophozoite stage) and $36 \mathrm{~h}$ thereafter (schizont stage).

\section{Isolation of mRNA interactome}

Parasites from mixed trophozoite and schizont cultures were extracted by saponin lysis of erythrocytes and were crosslinked on ice by $254 \mathrm{~nm}$ UV light for a total of $1200 \mathrm{~J} / \mathrm{cm}^{2}$ with two 2-min breaks with gentle mixing. The parasites were then washed in phosphate-buffered saline (PBS) and lysed in a lysis/binding buffer containing $100 \mathrm{mM}$ Tris- $\mathrm{HCl} \mathrm{pH} \mathrm{7.5,500} \mathrm{mM} \mathrm{LiCl,} 1 \mathrm{mM}$ EDTA, $0.5 \%$ LiDS, and $5 \mathrm{mM}$ dithiothreitol (DTT). Negative control samples were lysed in lysis/binding buffer without EDTA and treated with $400 \mu \mathrm{g}$ of RNase A (Life Technologies) and 10,000 units of RNase T1 (Ambion) for $30 \mathrm{~min}$ at $37{ }^{\circ} \mathrm{C}$, followed by the addition of EDTA to a final concentration of $1 \mathrm{mM}$. Samples were then allowed to bind to magnetic oligo $d(T)_{25}$ beads (New England Biolabs) by incubating at room temperature for $1 \mathrm{~h}$ with continuous mixing. The beads were washed twice in wash buffer I $(20 \mathrm{mM}$ Tris- $\mathrm{HCl}$ $\mathrm{pH}$ 7.5, $500 \mathrm{mM} \mathrm{LiCl}, 1 \mathrm{mM}$ EDTA, $0.1 \%$ LiDS, and $5 \mathrm{mM}$ DTT), twice in wash buffer II $(20 \mathrm{mM}$ Tris- $\mathrm{HCl}$ $\mathrm{pH} 7.5,500 \mathrm{mM} \mathrm{LiCl}$, and $1 \mathrm{mM}$ EDTA), and once in low-salt buffer $(20 \mathrm{mM}$ Tris- $\mathrm{HCl} \mathrm{pH}$ 7.5, $200 \mathrm{mM} \mathrm{LiCl}$, and $1 \mathrm{mM}$ EDTA). Proteins were eluted in elution buffer $\left(10 \mathrm{mM}\right.$ Tris- $\mathrm{HCl} \mathrm{pH} \mathrm{7.5,2} \mathrm{mM} \mathrm{CaCl}_{2}$, and 50 units of MNase) by incubation for $30 \mathrm{~min}$ at $37^{\circ} \mathrm{C}$, followed by the addition of Laemmli buffer and a 10-min incubation at $98{ }^{\circ} \mathrm{C}$. To control for the integrity of RNA after crosslinking, the total RNA was extracted from noncrosslinked and crosslinked parasites using TRIzol LS Reagent (Life Technologies) according to the manufacturer's instructions. RNA $(1 \mu \mathrm{g})$ was visualized on $1 \%$ agarose gel stained with ethidium bromide.

\section{RT-PCR}

Non-UV-crosslinked parasites and UV-crosslinked parasites were resuspended in lysis/binding buffer without EDTA and lysed by needle shearing. Parasite lysates and RNA capture samples were treated with Proteinase $\mathrm{K}$ for $30 \mathrm{~min}$ at $45{ }^{\circ} \mathrm{C}$. RNA was isolated using the RNeasy Kit (Qiagen) and treated twice with $4 \mathrm{U}$ DNase I (Life Technologies) per $10 \mu \mathrm{g}$ of RNA for $30 \mathrm{~min}$ at $37{ }^{\circ} \mathrm{C}$. DNase I was inactivated by the addition of EDTA to a final concentration of $1 \mathrm{mM}$. DNase-treated RNA was mixed with $0.1 \mu \mathrm{g}$ of random hexamers, $0.6 \mu \mathrm{g}$ of oligo(dT) 20 , and $2 \mu \mathrm{l} 10 \mathrm{mM}$ dNTP mix (Life Technologies) in a total volume of $10 \mu \mathrm{l}$, incubated for $10 \mathrm{~min}$ at $70{ }^{\circ} \mathrm{C}$, and then chilled on ice for $5 \mathrm{~min}$. This mixture was added to a solution containing $4 \mu \mathrm{l}$ 10X RT buffer, $8 \mu \mathrm{l} 20 \mathrm{mM} \mathrm{MgCl}_{2}, 4 \mu \mathrm{l}$ $0.1 \mathrm{M} \mathrm{DTT}, 2 \mu \mathrm{l} 20 \mathrm{U} / \mu \mathrm{l}$ RNaseOUT, and $1 \mu \mathrm{l} 200 \mathrm{U} / \mu \mathrm{l}$ SuperScript III Reverse Transcriptase (all from Life Technologies). First-strand cDNA was synthesized by incubating the sample for $10 \mathrm{~min}$ at $25^{\circ} \mathrm{C}, 50 \mathrm{~min}$ at $50{ }^{\circ} \mathrm{C}$, and finally $5 \mathrm{~min}$ at $85{ }^{\circ} \mathrm{C}$. DNA was amplified using KAPA HiFi DNA Polymerase by incubating for $5 \mathrm{~min}$ at $95^{\circ} \mathrm{C}$, followed by 30 cycles of $30 \mathrm{~s}$ at $98{ }^{\circ} \mathrm{C}, 30 \mathrm{~s}$ at $58^{\circ} \mathrm{C}$, and $30 \mathrm{~s}$ at $62{ }^{\circ} \mathrm{C}$, using the following primers: PF3D7_0725600 (18S rRNA), F: 5'-GAATTGACG GAAGGGCACC, R: 5' -CTTCCTTGTGTTAGACACAC; PF3D7_0826100 (E3 ubiquitin-protein ligase), F: 5' -CAG CATATACTGATGCTAAAG, R: 5'-AATGGTAGGAC TATAGTATTATT; PF3D7_1412600 (deoxyhypusine synthase), F: 5'-GATCAATGTGACATGTATTATC, R: 5'-CTCCGAGAATAATAATACCAG; PF3D7_1410400 (RAP1), F: 5'-CATCAGCTGCTGCAATTCT, R: 5'CGAAGCACTTCTCTTTGAGG; and PF3D7_1006200 (PfAlba3), F: 5'-GGATGTTTACAGGAAATGAAGAGA, R: 5'-GTTTGCTACAAAATCTGGGTG. The absence of genomic DNA contamination was validated using a primer set targeting PfAlba3 (PF3D7_1006200) from inside exon 1 to within exon 2. 


\section{Western blot analysis}

Non-UV-crosslinked and UV-crosslinked parasite lysates were treated with RNaseA and RNase T1 for $30 \mathrm{~min}$ at $37{ }^{\circ} \mathrm{C}$, followed by DNase treatment for $10 \mathrm{~min}$ at $37^{\circ} \mathrm{C}$. Samples were centrifuged at $13,000 \times \mathrm{g}$ for $2 \mathrm{~min}$. The lysate supernatants and capture samples were then loaded on an Any-kD SDS-PAGE gel (Bio-Rad) and run for $42 \mathrm{~min}$ at $150 \mathrm{~V}$. Proteins were transferred to a PVDF membrane for $40 \mathrm{~min}$ at $16 \mathrm{~V}$, stained using Anti-Histone H3 antibody (Abcam ab1791, 1:3,000) and Goat AntiRabbit IgG HRP Conjugate (Bio-Rad, 1:25,000), and visualized using the Bio-Rad ChemiDoc MP Gel Imager.

\section{Polysome isolations}

Polysomes were isolated in duplicate from $P$. falciparum cultures at the ring, trophozoite, and schizont stages according to a recently published protocol with minor modifications [74]. Cycloheximide was added to parasite-infected red blood cell cultures to a final concentration of $200 \mu \mathrm{M}$, followed by $10 \mathrm{~min}$ incubation at $37{ }^{\circ} \mathrm{C}$. Erythrocytes were then pelleted $(4 \mathrm{~min}$ at $660 \times \mathrm{g}$ ) and washed twice in PBS containing $200 \mu \mathrm{M}$ cycloheximide. After the last wash, the pellets were kept on ice and were subsequently lysed by adding 2.2 volumes of lysis buffer $(1 \%$ [v/v] Igepal CA-360 [Sigma-Aldrich] and $0.5 \%$ $[\mathrm{w} / \mathrm{v}]$ sodium deoxycholate in polysome buffer $[400 \mathrm{mM}$ potassium acetate, $25 \mathrm{mM}$ potassium HEPES $\mathrm{pH}$ 7.2, $15 \mathrm{mM}$ magnesium acetate, $200 \mu \mathrm{M}$ cycloheximide, $1 \mathrm{mM}$ $\mathrm{DTT}$, and $1 \mathrm{mM} \mathrm{AEBSF]}$ ). After $10 \mathrm{~min}$ incubation on ice, the lysates were centrifuged for $10 \mathrm{~min}$ at $20,000 \times \mathrm{g}$ at $4{ }^{\circ} \mathrm{C}$. The clarified lysates were then loaded on top of a sucrose cushion (1 M sucrose in polysome buffer) to concentrate the ribosomes. For large culture volumes, $20 \mathrm{ml}$ lysate was loaded on top of $6 \mathrm{ml}$ of sucrose cushion in $26 \mathrm{ml}$ polycarbonate ultracentrifuge tubes and then centrifuged for $3 \mathrm{~h}$ at $50,000 \mathrm{rpm}$ at $4{ }^{\circ} \mathrm{C}$ in a Type $70 \mathrm{Ti}$ rotor (Beckman Coulter, Brea, CA, USA). For small culture volumes, $4 \mathrm{ml}$ lysate was loaded atop $1.25 \mathrm{ml}$ of sucrose cushion in $5 \mathrm{ml}$ polyallomer ultracentrifuge tubes and then centrifuged for $123 \mathrm{~min}$ at $50,000 \mathrm{rpm}$ at $4{ }^{\circ} \mathrm{C}$ in an $\mathrm{SW} 55 \mathrm{Ti}$ rotor (Beckman Coulter). Ribosome pellets were resuspended in polysome buffer, incubated for at least $30 \mathrm{~min}$ at $4{ }^{\circ} \mathrm{C}$ to allow complete ribosome resuspension, and centrifuged for $10 \mathrm{~min}$ at $12,000 \times \mathrm{g}$ at $4{ }^{\circ} \mathrm{C}$. The ribosome suspension was layered on top of a 4.5-ml continuous linear 15-60\% sucrose $[\mathrm{w} / \mathrm{v}]$ gradient in polysome buffer and centrifuged for $1.5 \mathrm{~h}$ at $50,000 \mathrm{rpm}$ at $4{ }^{\circ} \mathrm{C}$ in an SW 55 Ti rotor. Fractions of $400 \mu \mathrm{l}$ were collected using an UA-5 UV Detector and Model 185 Gradient Fractionator (ISCO, Lincoln, NE, USA). To control for co-sedimentation of proteins in polysome fractions, polysomes were disrupted by resuspension of the ribosome pellets in buffer containing $25 \mathrm{mM}$ EDTA.

For the isolation of cytoplasmic fractions, synchronized parasite cultures were lysed by incubation in
$0.15 \%$ saponin for $10 \mathrm{~min}$ on ice. Parasites were centrifuged at $3234 \times \mathrm{g}$ for $10 \mathrm{~min}$ at $4{ }^{\circ} \mathrm{C}$ and washed three times with PBS. After the last wash, the parasites were resuspended in PBS, transferred to a microcentrifuge tube, and centrifuged for $5 \mathrm{~min}$ at $2500 \times \mathrm{g}$ at $4{ }^{\circ} \mathrm{C}$. Subsequently, the parasite pellet was resuspended in $1.5 \mathrm{X}$ volume of cytoplasmic lysis buffer $(0.65 \%$ Igepal CA-360, $10 \mathrm{mM}$ Tris- $\mathrm{HCl} \mathrm{pH}$ 7.5, $150 \mathrm{mM} \mathrm{NaCl}, 1 \mathrm{mM}$ EDTA, $1 \mathrm{mM}$ EGTA, $2 \mathrm{mM}$ AEBSF, and EDTA-free Protease Inhibitor Cocktail [Roche]) and lysed by passing through a $26 \mathrm{G} \times 1 \frac{1}{2}$-in. needle 15 times. Parasite nuclei were centrifuged at $14,000 \times \mathrm{g}$ for $15 \mathrm{~min}$ at $4{ }^{\circ} \mathrm{C}$, followed by collection of the supernatant containing the cytoplasmic extract.

\section{Multidimensional protein identification technology (MudPIT)}

Proteins were precipitated with $20 \%$ trichloroacetic acid (TCA). The resulting pellet was washed once with $10 \%$ TCA and twice with cold acetone. The TCA-precipitated protein pellet (about $50 \mu \mathrm{g}$ ) was solubilized in Tris- $\mathrm{HCl}$ $\mathrm{pH} 8.5$ and $8 \mathrm{M}$ urea. TCEP (Tris(2-carboxyethyl)phosphine hydrochloride, Pierce) and CAM (chloroacetamide, Sigma) were added to a final concentration of $5 \mathrm{mM}$ and $10 \mathrm{mM}$, respectively. The protein suspension was digested overnight at $37^{\circ} \mathrm{C}$ using Endoproteinase Lys-C at 1:50 w/w (Roche). The sample was brought to a final concentration of $2 \mathrm{M}$ urea and $2 \mathrm{mM} \mathrm{CaCl}_{2}$ before performing a second overnight digestion at $37{ }^{\circ} \mathrm{C}$ using trypsin (Promega) at $1: 100 \mathrm{w} / \mathrm{w}$. Formic acid ( $5 \%$ final) was added to stop the reactions. The sample was loaded on a split-triple-phase fused-silica micro-capillary column [75] and placed in-line with a linear ion trap mass spectrometer (LTQ) (Thermo Scientific), coupled with a Quaternary Agilent 1260 Series HPLC system. Polysome replicate 1 samples and the ring stage control sample were analyzed on a Velos Pro ion-trap instrument using the LTQ, while all other samples were analyzed using LTQ only. All samples were run in low resolution mode. A fully automated 10-step chromatography run (for a total of $20 \mathrm{~h}$ ) was carried out, as described in [76]. Each full MS scan (400-1600 m/z) was followed by five data-dependent MS/MS scans. The number of the micro scans was set to 1 both for MS and MS/MS. The dynamic exclusion settings used were as follows: repeat count 2; repeat duration $30 \mathrm{~s}$; exclusion list size 500 and exclusion duration $120 \mathrm{~s}$, while the minimum signal threshold was set to 100. The MS/MS data set was searched using SEQUEST [77] against a database of 72,358 sequences, consisting of 5487 P. falciparum non-redundant proteins (downloaded from PlasmoDB on 12 July 2012), 30,536 H. sapiens non-redundant proteins (downloaded from NCBI on 27 August 2012), 177 usual contaminants (such as human keratins, IgGs, and proteolytic enzymes), and, to estimate false discovery rates (FDRs), 36,179 randomized 
amino acid sequences derived from each non-redundant protein entry. To account for alkylation by CAM, $57 \mathrm{Da}$ were added statically to the cysteine residues. To account for the oxidation of methionine residues to methionine sulfoxide (which can occur as an artifact during sample processing), $16 \mathrm{Da}$ were added as a differential modification to the methionine residue. Peptide/spectrum matches were sorted and selected using DTASelect/CONTRAST [78]. Proteins had to be detected by one peptide with two independent spectra, leading to average FDRs at the protein and spectral levels of $0.45 \%$ (range, $0-1.13 \%$ ) and $0.12 \%$ (range, $0-0.33 \%$ ), respectively, for the interactome capture experiments and $1.26 \%$ (range, $0.15-2.56 \%$ ) and $0.09 \%$ (range, $0.01-0.17 \%$ ), respectively, for the polysome isolation experiments. To estimate relative protein levels and to account for peptides shared between proteins, normalized spectral abundance factors (dNSAFs) were calculated for each detected protein, as described in [79].

\section{MudPIT data analysis}

A total of four independent mRNA-interactome capture experiments were performed: two biological replicates each for trophozoite-stage and schizont-stage parasites. Enrichment of RBPs in each individual experiment was defined as detection of two or more spectra of that protein in the capture sample and a more than twofold higher normalized abundance (dNSAF) as compared to the control RNase sample. Data from the four independent experiments were then combined, and proteins that were enriched in at least two independent experiments were considered candidate mRBPs. Proteins that were detected at a higher abundance in the control samples than in the corresponding capture sample were considered depleted. Ribosomal proteins were considered contaminants and were removed from the list of detected proteins. Lists of all proteins that were detected in our samples and individual peptide/spectral counts are provided in Additional file 5. The QSpec statistical package (v. 1.2.2) was also used to define a statistically significant list of proteins enriched in the capture experiments (combining replicates from trophozoites and schizonts) compared to controls. Distributed spectral counts and lengths of the detected proteins were inputted to the online interface (http://www.nesvilab.org/qspec.php/). QSpec uses a Bayesian hierarchical model to derive statistical information for estimates of mean and variance across all proteins when limited numbers of replicates are available [80]. Proteins with a $\log _{2}$ (FoldChange) $>0$ and FDRup values $<0.05$ were considered significantly enriched.

The likelihood that highly abundant proteins were detected as a result of contamination was assessed by comparing the sum of spectral counts from all capture samples to the sum of all spectra from an existing mass spectrometry data set [46] using the chi-square test with
Benjamini-Hochberg correction for multiple testing in $\mathrm{R}$ v2.7.0.

Polysomes were isolated in duplicate from three parasite stages (ring, trophozoite, schizont). Polysomeassociated proteins were defined as proteins that were detected in both series of replicates and that were more than twofold enriched compared to cytoplasmic fractions in at least half of the samples in which the protein was detected. Lists of all proteins that were detected in our samples and individual peptide/spectral counts are provided in Additional file 7.

\section{GO and Pfam domain enrichment analysis}

The enrichment of Gene Ontology (GO) terms was analyzed using the software package topGO (written in $\mathrm{R}$ and maintained by the BioConductor project) [81]. For each GO domain (i.e., cellular component, biological process, or molecular function), we compared the proteins identified by MudPIT to the full proteome of $P$. falciparum using the "classic" algorithm in combination with a Fisher's exact test. GO terms with a $p$ value $<0.01$ were reported. Enrichment of Pfam domains was tested using the hypergeometric test with Benjamini-Hochberg correction for multiple testing in R v2.7.0, as described in [43].

\section{Additional files}

Additional file 1: List of RNA-binding domains used for HMM searches. (XLSX $67 \mathrm{~kb}$ )

Additional file 2: List of predicted RNA-binding proteins in P. falciparum. (XLSX $112 \mathrm{~kb}$ )

Additional file 3: Document containing supplementary Figures S1-S10 and their legends. (PDF $1225 \mathrm{~kb}$ )

Additional file 4: Comparative analysis of the abundance of RNA-binding domains in various organisms. (XLSX $191 \mathrm{~kb}$ )

Additional file 5: Experimentally captured RNA-binding proteins at the trophozoite and schizont stages, including mass spectrometry data. (XLSX $1361 \mathrm{~kb})$

Additional file 6: Enriched $\mathrm{GO}$ terms and enrichment of mRNA-binding domains among experimentally captured RNA-binding proteins. (XLSX $45 \mathrm{~kb}$ )

Additional file 7: Proteins associated with polysomes during the IDC, including mass spectrometry data. (XLSX $1246 \mathrm{~kb}$ )

\section{Acknowledgements \\ The following reagent was obtained through the MR4 as part of the BEI Resources Repository, NIAID, NIH: Plasmodium falciparum strains 3D7 (MRA-102) deposited by D.J. Carucci. \\ Funding \\ This study was financially supported by the National Institutes of Health (grants R01 Al85077-01A1 and R01 Al06775-01 to KGLR) and the University of California, Riverside (NIFA-Hatch-225935 to KGLR). The funding bodies had no role in the design of the study, in collection, analysis, and interpretation of data, or in writing the manuscript.}

Availability of data and material

The complete MudPIT mass spectrometry data (raw files, peak files, search files, as well as DTASelect result files) can be obtained from the MassIVE database (ftp://massive.ucsd.edu/) or ProteomeXchange (http///www.proteomexchange.org/) using the accession numbers MSV000079612/PXD003866 and MSV000079613/ 
PXD003867 for the mRNA-associated proteins and the polysome-associated protein data sets, respectively, as usernames with password EVB12529. Original data underlying this manuscript can also be accessed from the Stowers Original Data Repository at http://www.stowers.org/research/publications/libpb-1054. $\mathrm{R}$ scripts for the chi-square test and the hypergeometric test are available in GitHub under the MIT license via https://github.com/embunnik/chi_square/ releases/tag/v1.0 (doi:10.6084/m9.figshare.3439325.v1) and https://github.com/ embunnik/hypergeometric/releases/tag/v1.0 (doi:10.6084/m9.figshare.343943.v1).

\section{Authors' contributions}

$E M B$ and KGLR designed the project; EMB, GB, and AS performed experiments; $E M B, A S$, and LF performed data analysis; JP maintained $P$. falciparum cultures and assisted in experimental procedures; EMB and KGLR wrote the manuscript; KGLR was responsible for funding acquisition. All authors read and approved the final manuscript.

\section{Competing interests}

The authors declare that they have no competing interests.

\section{Ethics approval and consent to participate}

Ethics approval is not applicable for this study.

\section{Author details}

'Department of Cell Biology and Neuroscience, University of California, Riverside, 900 University Avenue, Riverside, CA 92521, USA. ${ }^{2}$ Stowers Institute for Medical Research, 1000 E. 50th Street, Kansas City, MO 64110, USA.

\section{Received: 31 May 2016 Accepted: 20 June 2016}

\section{Published online: 05 July 2016}

\section{References}

1. WHO. The World Malaria Report. 2015. http://www.who.int/malaria/ publications/world-malaria-report-2015/report/en/

2. Ashley EA, Dhorda M, Fairhurst RM, Amaratunga C, Lim P, Suon S, Sreng S, Anderson JM, Mao S, Sam B, et al. Spread of artemisinin resistance in Plasmodium falciparum malaria. N Engl J Med. 2014;371:411-23.

3. Takala-Harrison S, Jacob CG, Arze C, Cummings MP, Silva JC, Dondorp AM, Fukuda MM, Hien TT, Mayxay M, Noedl H, et al. Independent emergence of artemisinin resistance mutations among Plasmodium falciparum in Southeast Asia. J Infect Dis. 2015;211:670-9.

4. Gardner MJ, Hall N, Fung E, White O, Berriman M, Hyman RW, Carlton JM, Pain A, Nelson KE, Bowman S, et al. Genome sequence of the human malaria parasite Plasmodium falciparum. Nature. 2002;419:498-511.

5. Bozdech Z, Llinas M, Pulliam BL, Wong ED, Zhu J, DeRisi JL. The transcriptome of the intraerythrocytic developmental cycle of Plasmodium falciparum. PLoS Biol. 2003;1:E5.

6. Le Roch KG, Zhou Y, Blair PL, Grainger M, Moch JK, Haynes JD, De La Vega P, Holder AA, Batalov S, Carucci DJ, Winzeler EA. Discovery of gene function by expression profiling of the malaria parasite life cycle. Science. 2003;301:1503-8.

7. Young JA, Winzeler EA. Using expression information to discover new drug and vaccine targets in the malaria parasite Plasmodium falciparum. Pharmacogenomics. 2005;6:17-26.

8. Balaji S, Babu MM, lyer LM, Aravind L. Discovery of the principal specific transcription factors of Apicomplexa and their implication for the evolution of the AP2-integrase DNA binding domains. Nucleic Acids Res. 2005;33:3994-4006.

9. Bischoff E, Vaquero C. In silico and biological survey of transcription-associated proteins implicated in the transcriptional machinery during the erythrocytic development of Plasmodium falciparum. BMC Genomics. 2010;11:34.

10. Carlton JM, Adams JH, Silva JC, Bidwell SL, Lorenzi H, Caler E, Crabtree J, Angiuoli SV, Merino EF, Amedeo P, et al. Comparative genomics of the neglected human malaria parasite Plasmodium vivax. Nature. 2008;455:757-63.

11. Coulson RM, Hall N, Ouzounis CA. Comparative genomics of transcriptional control in the human malaria parasite Plasmodium falciparum. Genome Res. 2004;14:1548-54

12. Duffy MF, Selvarajah SA, Josling GA, Petter M. The role of chromatin in Plasmodium gene expression. Cell Microbiol. 2012;14:819-28.

13. Salcedo-Amaya AM, Hoeijmakers WA, Bartfai R, Stunnenberg HG. Malaria: could its unusual epigenome be the weak spot? Int J Biochem Cell Biol. 2010;42:781-4

14. Bunnik EM, Chung DW, Hamilton M, Ponts N, Saraf A, Prudhomme J, Florens L, Le Roch KG. Polysome profiling reveals translational control of gene expression in the human malaria parasite Plasmodium falciparum. Genome Biol. 2013;14:R128.

15. Caro F, Ahyong V, Betegon M, DeRisi JL. Genome-wide regulatory dynamics of translation in the asexual blood stages. Elife. 2014:3:e04106.

16. Foth BJ, Zhang N, Mok S, Preiser PR, Bozdech Z. Quantitative protein expression profiling reveals extensive post-transcriptional regulation and post-translational modifications in schizont-stage malaria parasites. Genome Biol. 2008;9:R177.

17. Le Roch KG, Johnson JR, Florens L, Zhou Y, Santrosyan A, Grainger M, Yan SF, Williamson KC, Holder AA, Carucci DJ, et al. Global analysis of transcript and protein levels across the Plasmodium falciparum life cycle. Genome Res. 2004; 14:2308-18

18. Aravind L, lyer LM, Wellems TE, Miller LH. Plasmodium biology: genomic gleanings. Cell. 2003;115:771-85.

19. Zhang M, Fennell C, Ranford-Cartwright L, Sakthivel R, Gueirard P, Meister S, Caspi A, Doerig C, Nussenzweig RS, Tuteja R, et al. The Plasmodium eukaryotic initiation factor-2alpha kinase IK2 controls the latency of sporozoites in the mosquito salivary glands. J Exp Med. 2010;207:1465-74.

20. Muller K, Matuschewski K, Silvie O. The Puf-family RNA-binding protein Puf2 controls sporozoite conversion to liver stages in the malaria parasite. PLoS One. 2011;6:e19860.

21. Gomes-Santos CS, Braks J, Prudencio M, Carret C, Gomes AR, Pain A, Feltwell T, Khan S, Waters A, Janse $C$, et al. Transition of Plasmodium sporozoites into liver stage-like forms is regulated by the RNA binding protein Pumilio. PLoS Pathog 2011;7:e1002046.

22. Lindner SE, Mikolajczak SA, Vaughan AM, Moon W, Joyce BR, Sullivan Jr WJ, Kappe SH. Perturbations of Plasmodium Puf2 expression and RNA-seq of Puf2-deficient sporozoites reveal a critical role in maintaining RNA homeostasis and parasite transmissibility. Cell Microbiol. 2013;15:1266-83.

23. Guerreiro A, Deligianni E, Santos JM, Silva PA, Louis C, Pain A, Janse CJ, Franke-Fayard B, Carret CK, Siden-Kiamos I, Mair GR. Genome-wide RIP-Chip analysis of translational repressor-bound mRNAs in the Plasmodium gametocyte. Genome Biol. 2014;15:493.

24. Mair GR, Braks JA, Garver LS, Wiegant JC, Hall N, Dirks RW, Khan SM, Dimopoulos G, Janse CJ, Waters AP. Regulation of sexual development of Plasmodium by translational repression. Science. 2006:313:667-9.

25. Mair GR, Lasonder E, Garver LS, Franke-Fayard BM, Carret CK, Wiegant JC, Dirks RW, Dimopoulos G, Janse CJ, Waters AP. Universal features of post-transcriptional gene regulation are critical for Plasmodium zygote development. PLoS Pathog. 2010;6:e1000767.

26. Miao J, Fan Q, Parker D, Li X, Li J, Cui L. Puf mediates translation repression of transmission-blocking vaccine candidates in malaria parasites. PLoS Pathog. 2013;9:e1003268

27. Balu B, Maher SP, Pance A, Chauhan C, Naumov AV, Andrews RM, Ellis PD, Khan SM, Lin JW, Janse CJ, et al. CCR4-associated factor 1 coordinates the expression of Plasmodium falciparum egress and invasion proteins. Eukaryot Cell. 2011:10:1257-63.

28. Vembar SS, Macpherson CR, Sismeiro O, Coppee JY, Scherf A. The PfAlba1 RNA-binding protein is an important regulator of translational timing in Plasmodium falciparum blood stages. Genome Biol. 2015;16:212.

29. Eshar S, Altenhofen L, Rabner A, Ross P, Fastman Y, Mandel-Gutfreund Y, Karni R, Llinas M, Dzikowski R. PfSR1 controls alternative splicing and steady-state RNA levels in Plasmodium falciparum through preferential recognition of specific RNA motifs. Mol Microbiol. 2015;96:1283-97.

30. Reddy BP, Shrestha S, Hart KJ, Liang X, Kemirembe K, Cui L, Lindner SE. A bioinformatic survey of RNA-binding proteins in Plasmodium. BMC Genomics. 2015;16:890.

31. Gerstberger $\mathrm{S}$, Hafner M, Tuschl T. A census of human RNA-binding proteins. Nat Rev Genet. 2014;15:829-45.

32. Mitchell SF, Parker R. Principles and properties of eukaryotic mRNPs. Mol Cell. 2014;54:547-58.

33. He W, Parker R. Functions of Lsm proteins in mRNA degradation and splicing. Curr Opin Cell Biol. 2000;12:346-50.

34. Lopez-Barragan MJ, Lemieux J, Quinones M, Williamson KC, Molina-Cruz A Cui K, Barillas-Mury C, Zhao K, Su XZ. Directional gene expression and antisense transcripts in sexual and asexual stages of Plasmodium falciparum. BMC Genomics. 2011;12:587.

35. Wongsombat C, Aroonsri A, Kamchonwongpaisan S, Morgan HP, Walkinshaw MD, Yuthavong Y, Shaw PJ. Molecular characterization of Plasmodium falciparum Bruno/CELF RNA binding proteins. Mol Biochem Parasitol. 2014;198:1-10. 
36. Braun L, Cannella D, Ortet P, Barakat M, Sautel CF, Kieffer S, Garin J, Bastien O, Voinnet $\mathrm{O}$, Hakimi MA. A complex small RNA repertoire is generated by a plant/fungal-like machinery and effected by a metazoan-like Argonaute in the single-cell human parasite Toxoplasma gondii. PLoS Pathog. 2010;6:e1000920.

37. Wang J, Liu X, Jia B, Lu H, Peng S, Piao X, Hou N, Cai P, Yin J, Jiang N, Chen Q. A comparative study of small RNAs in Toxoplasma gondii of distinct genotypes. Parasit Vectors. 2012;5:186.

38. Kolev NG, Tschudi C, Ullu E. RNA interference in protozoan parasites: achievements and challenges. Eukaryot Cell. 2011;10:1156-63.

39. Lee I, Hong W. RAP - a putative RNA-binding domain. Trends Biochem Sci. 2004;29:567-70

40. Mitchell SF, Jain S, She M, Parker R. Global analysis of yeast mRNPs. Nat Struct Mol Biol. 2013;20:127-33.

41. Castello A, Fischer B, Eichelbaum K, Horos R, Beckmann BM, Strein C, Davey NE, Humphreys DT, Preiss T, Steinmetz LM, et al. Insights into RNA biology from an atlas of mammalian mRNA-binding proteins. Cell. 2012;149:1393-406.

42. Baltz AG, Munschauer M, Schwanhausser B, Vasile A, Murakawa Y, Schueler M Youngs N, Penfold-Brown D, Drew K, Milek M, et al. The mRNA-bound proteome and its global occupancy profile on protein-coding transcripts. Mol Cell. 2012;46:674-90.

43. Matia-Gonzalez AM, Laing EE, Gerber AP. Conserved mRNA-binding proteomes in eukaryotic organisms. Nat Struct Mol Biol. 2015;22:1027-33.

44. Beckmann BM, Horos R, Fischer B, Castello A, Eichelbaum K, Alleaume AM, Schwarzl T, Curk T, Foehr S, Huber W, et al. The RNA-binding proteomes from yeast to man harbour conserved enigmRBPs. Nat Commun. 2015:6:10127.

45. Wessels HH, Imami K, Baltz AG, Kolinksi M, Beldovskaya A, Selbach M, Small S, Ohler U, Landthaler M. The mRNA-bound proteome of the early fly embryo. Genome Res. 2016. doi:10.1101/gr.200386.115.

46. Oehring SC, Woodcroft BJ, Moes S, Wetzel J, Dietz O, Pulfer A, et al. Organellar proteomics reveals hundreds of novel nuclear proteins in the malaria parasite Plasmodium falciparum. Genome Biol. 2012;13:R108

47. Tarique M, Ahmad M, Ansari A, Tuteja R. Plasmodium falciparum DOZI, an RNA helicase interacts with elF4E. Gene. 2013;522:46-59.

48. Wong W, Bai XC, Brown A, Fernandez IS, Hanssen E, Condron M, Tan YH, Baum J, Scheres SH. Cryo-EM structure of the Plasmodium falciparum $80 \mathrm{~S}$ ribosome bound to the anti-protozoan drug emetine. Elife. 2014;3:e03080

49. Sun M, Li W, Blomqvist K, Das S, Hashem Y, Dvorin JD, Frank J. Dynamical features of the Plasmodium falciparum ribosome during translation. Nucleic Acids Res. 2015;43:10515-24.

50. De Gaudenzi JG, Noe G, Campo VA, Frasch AC, Cassola A. Gene expression regulation in trypanosomatids. Essays Biochem. 2011;51:31-46.

51. Queiroz R, Benz C, Fellenberg K, Hoheisel JD, Clayton C. Transcriptome analysis of differentiating trypanosomes reveals the existence of multiple post-transcriptional regulons. BMC Genomics. 2009;10:495.

52. Ouellette M, Papadopoulou B. Coordinated gene expression by posttranscriptional regulons in African trypanosomes. J Biol. 2009:8:100.

53. Kramer $\mathrm{S}$, Carrington M. Trans-acting proteins regulating mRNA maturation, stability and translation in trypanosomatids. Trends Parasitol. 2011;27:23-30.

54. Simone LE, Keene JD. Mechanisms coordinating ELAV/Hu mRNA regulons. Curr Opin Genet Dev. 2013;23:35-43.

55. Balu B, Singh N, Maher SP, Adams JH. A genetic screen for attenuated growth identifies genes crucial for intraerythrocytic development of Plasmodium falciparum. PLoS One. 2010;5:e13282.

56. Baragana B, Hallyburton I, Lee MC, Norcross NR, Grimaldi R, Otto TD, Proto WR, Blagborough AM, Meister S, Wirjanata G, et al. A novel multiple-stage antimalarial agent that inhibits protein synthesis. Nature. 2015;522:315-20.

57. Friedersdorf MB, Keene JD. Advancing the functional utility of PAR-CLIP by quantifying background binding to mRNAs and IncRNAs. Genome Biol. 2014;15:R2.

58. Van Nostrand EL, Pratt GA, Shishkin AA, Gelboin-Burkhart C, Fang MY, Sundararaman B, Blue SM, Nquyen TB, Surka C, Elkins K, et al. Robust transcriptome-wide discovery of RNA-binding protein binding sites with enhanced CLIP (eCLIP). Nat Methods. 2016;13:508-14.

59. Date SV, Stoeckert Jr CJ. Computational modeling of the Plasmodium falciparum interactome reveals protein function on a genome-wide scale. Genome Res. 2006;16:542-9.

60. Chene A, Vembar SS, Riviere L, Lopez-Rubio JJ, Claes A, Siegel TN, Sakamoto H, Scheidig-Benatar C, Hernandez-Rivas R, Scherf A. PfAlbas constitute a new eukaryotic DNA/RNA-binding protein family in malaria parasites. Nucleic Acids Res. 2012:40:3066-77.
61. Buchan JR, Parker R. Eukaryotic stress granules: the ins and outs of translation. Mol Cell. 2009;36:932-41.

62. Decker CJ, Parker R. P-bodies and stress granules: possible roles in the control of translation and mRNA degradation. Cold Spring Harb Perspect Biol. 2012;4:a012286.

63. Anderson P, Kedersha N. RNA granules: post-transcriptional and epigenetic modulators of gene expression. Nat Rev Mol Cell Biol. 2009;10:430-6.

64. Miller JE, Reese JC. Ccr4-Not complex: the control freak of eukaryotic cells. Crit Rev Biochem Mol Biol. 2012;47:315-33.

65. Preissler S, Reuther J, Koch M, Scior A, Bruderek M, Frickey T, Deuerling E. Not4-dependent translational repression is important for cellular protein homeostasis in yeast. EMBO J. 2015;34:1905-24.

66. Engel SR, Dietrich FS, Fisk DG, Binkley G, Balakrishnan R, Costanzo MC, Dwight SS, Hitz BC, Karra K, Nash RS, et al. The reference genome sequence of Saccharomyces cerevisiae: then and now. G3 (Bethesda). 2014:4:389-98.

67. Cunningham F, Amode MR, Barrell D, Beal K, Billis K, Brent S, Carvalho-Silva D, Clapham P, Coates G, Fitzgerald S, et al. Ensembl 2015. Nucleic Acids Res. 2015:43:D662-9.

68. Finn RD, Bateman A, Clements J, Coggill P, Eberhardt RY, Eddy SR, Heger A, Hetherington K, Holm L, Mistry J, et al. Pfam: the protein families database. Nucleic Acids Res. 2014;42:D222-30.

69. Eddy SR. Profile hidden Markov models. Bioinformatics. 1998;14:755-63.

70. R Code Team. R: A language and environment for statistical computing. $R$ Foundation for Statistical Computing, Vienna, Austria. 2014. https://www. r-project.org/.

71. Fang $H$, Gough J. A domain-centric solution to functional genomics via dcGO Predictor. BMC Bioinformatics. 2013;14 Suppl 3:S9.

72. Trager W, Jensen JB. Human malaria parasites in continuous culture. Science. 1976;193:673-5.

73. Lambros C, Vanderberg JP. Synchronization of Plasmodium falciparum erythrocytic stages in culture. J Parasitol. 1979;65:418-20.

74. Lacsina JR, LaMonte G, Nicchitta CV, Chi JT. Polysome profiling of the malaria parasite Plasmodium falciparum. Mol Biochem Parasitol. 2011:179:42-6.

75. McDonald WH, Ohi R, Miyamoto DT, Mitchison TJ, Yates JR. Comparison of three directly coupled HPLC MS/MS strategies for identification of proteins from complex mixtures: single-dimension LCMS/MS, 2-phase MudPIT, and 3-phase MudPIT. Internat J Mass Spectrometry. 2002;219:245-51.

76. Florens $L$, Washburn MP. Proteomic analysis by multidimensional protein identification technology. Methods Mol Biol. 2006;328:159-75.

77. Eng JK, McCormack AL, Yates JR. An approach to correlate tandem mass spectral data of peptides with amino acid sequences in a protein database. J Am Soc Mass Spectrom. 1994;5:976-89.

78. Tabb DL, McDonald WH, Yates 3rd JR. DTASelect and Contrast: tools for assembling and comparing protein identifications from shotgun proteomics. J Proteome Res. 2002;1:21-6.

79. Zhang Y, Wen Z, Washburn MP, Florens L. Refinements to label free proteome quantitation: how to deal with peptides shared by multiple proteins. Anal Chem. 2010;82:2272-81.

80. Choi H, Fermin D, Nesvizhskii Al. Significance analysis of spectral count data in label-free shotgun proteomics. Mol Cell Proteomics. 2008;7:2373-85.

81. Alexa A, Rahnenfuhrer J. topGO: enrichment analysis for gene ontology. R package version 2.6.0. 2010. http://www.bioconductor.org/packages/release/ bioc/html/topGO.html.

\section{Submit your next manuscript to BioMed Central and we will help you at every step:}

- We accept pre-submission inquiries

- Our selector tool helps you to find the most relevant journal

- We provide round the clock customer support

- Convenient online submission

- Thorough peer review

- Inclusion in PubMed and all major indexing services

- Maximum visibility for your research

Submit your manuscript at www.biomedcentral.com/submit 